\title{
Modeling of wave-induced irradiance variability in the upper ocean mixed layer
}

\author{
M. Hieronymi ${ }^{1,2}$, A. Macke $^{2}$, and O. Zielinski ${ }^{3}$ \\ ${ }^{1}$ Helmholtz Centre for Ocean Research, GEOMAR, Kiel, Germany \\ ${ }^{2}$ Leibniz Institute for Tropospheric Research, IFT, Leipzig, Germany \\ ${ }^{3}$ Institute for Chemistry and Biology of the Marine Environment, ICBM, Oldenburg, Germany \\ Correspondence to: A. Macke (macke@tropos.de)
}

Received: 25 August 2011 - Published in Ocean Sci. Discuss.: 24 October 2011

Revised: 10 January 2012 - Accepted: 24 January 2012 - Published: 1 March 2012

\begin{abstract}
A Monte Carlo based radiative transfer model has been developed for calculating the availability of solar radiation within the top $100 \mathrm{~m}$ of the ocean. The model is optimized for simulations of spatial high resolution downwelling irradiance $E_{\mathrm{d}}$ fluctuations that arise from the lensing effect of waves at the water surface. In a first step the accuracy of simulation results has been verified by measurements of the oceanic underwater light field and through intercomparison with an established radiative transfer model. Secondly the potential depth-impact of nonlinear shaped single waves, from capillary to swell waves, is assessed by considering the most favorable conditions for light focusing, i.e. monochromatic light at $490 \mathrm{~nm}$, very clear oceanic water with a low chlorophyll $a$ content of $0.1 \mathrm{mg} \mathrm{m}^{-3}$ and high sun elevation. Finally light fields below irregular wave profiles accounting for realistic sea states were simulated. Our simulation results suggest that under open ocean conditions light flashes with $50 \%$ irradiance enhancements can appear down to $35 \mathrm{~m}$ depth, and light variability in the range of $\pm 10 \%$ compared to the mean $E_{\mathrm{d}}$ is still possible in $100 \mathrm{~m}$ depth.
\end{abstract}

\section{Introduction}

The supply of solar energy to the upper ocean is subject to highly erratic fluctuations, e.g. depending on the sun position, the spectral range of radiation, cloud conditions, water properties and the water depth. In addition, very intense fluctuations occur when sunlight is focused and defocused due to the lensing effect of waves on the water surface, which is the subject of this paper. The variability of spectral irra- diance affects several processes in the photic zone of the upper ocean, including photosynthesis of marine phytoplankton (e.g. Walsh and Legendre, 1983; Falkowski, 1984; Wozniak et al., 2003; Dickey et al., 2011).

Several experimental studies in the past were devoted to characterize the statistical properties of fluctuations of the underwater radiance and irradiance field. Field measurements show that the fluctuations of downwelling irradiance $E_{\mathrm{d}}$ are at maximum in clear waters, under clear skies, with high sun altitudes, at wavelengths in the blue-green spectral range, and near the surface within the first ten metres (Dera and Gordon, 1968; Snyder and Dera, 1970; Nikolayev and Prokopov, 1977; Dera and Stramski, 1986). The latest radiometric measurements show very intense fluctuations in irradiance (at $532 \mathrm{~nm}$ wavelength and at $0.86 \mathrm{~m}$ depth) with peaks exceeding the mean irradiance by a factor of 13 (Gernez et al., 2011). The three-dimensional profile of the water surface determines the light variability within the water column. Different kinds of surface waves, from capillary to fully developed ocean waves, generate characteristic spatiotemporal light patterns at corresponding optical depths (e.g. Nikolayev and Yakubenko, 1978b; Fraser et al., 1980; Wijesekera et al., 2005; Hieronymi and Macke, 2010). Thus, the statistical characteristics of the underwater light field correlate with wind and sea state conditions (e.g. Nikolayev and Yakubenko, 1978a; Gernez and Antoine, 2009). According to Dera and Stramski (1986) and Gernez and Antoine (2009), the most effective waves in terms of their lensing efficiency are caused by light winds between 1 and $5 \mathrm{~m} \mathrm{~s}^{-1}$. But there are uncertainties concerning the effectiveness and influence of ocean waves on the underwater light field, since many of 
the published data sets have been collected relatively close to the coasts, where generally sea states and waves are not fully developed compared to the open ocean. This issue is addressed within this paper.

The impact of a wind-roughened sea surface on the mean conditions of the underwater light regime and the mechanisms of the wave lensing effect have been investigated numerically over a long period. Wind affects the surface albedo (irradiance reflectance) and the in-water transmission angles of incident light (Preisendorfer and Mobley, 1986), which influences the mean downwelling irradiance in the water. This phenomenon is taken into account in classical atmosphere-ocean radiative transfer models, where stochastic wind-depending wave slope distributions by Cox and Munk (1954) are implemented (e.g. Plass et al., 1975; Mobley et al., 1993). Up to now, this description of the rough air-sea interface is generally applied for example in the HydroLight software by Mobley (1994) or in the MOMO code by Fell and Fischer (2001). The extreme variance of radiative fluxes near the surface due to the lensing effect cannot be adequately simulated with randomly distributed wave slopes. For this task a well-defined wave structure is needed. The focusing effect of simplified single waves, for example, was studied by means of geometric ray tracing by Schenck (1957), Nikolayev and Khulapov (1975), Dera and Stramski (1988), and Zaneveld et al. (2001). The irregular character of the underwater irradiance distribution is taken into account by implementation of random sea surfaces into the models, that are represented as a superposition of elementary waves from a wave spectrum (e.g. Nikolayev et al., 1972; Yakubenko and Nikolayev, 1977; Weber, 2010; You et al., 2010).

Regarding previous modeling works three points should be improved: (1) the description of the sea surfaces should be more realistic, accounting for all spectral ranges of ocean waves; furthermore the actual wave elevations (in zdirection) should be explicitly implemented into the radiative transfer model. (2) The model should allow for scattering and absorption of light within the water column, and (3) the depth resolution of the underwater light field should be significantly enhanced at all relevant water depths. The present work gives an approach for solving these issues. We introduce a novel Monte Carlo (MC) radiative transfer model, which is optimized for fast and spatial high-resolution simulations of the underwater light field below any user-defined shape of the water surface. By means of the model, we show the impact of nonlinear shaped single waves and examples with realistic wave profiles that consist of all wave sizes from capillary to swell waves. The two-dimensional MC model covers a large spatial light field with high resolution and it considers the actual vertical wave deflection. The model is based on homogeneous inherent optical properties (IOPs) of very clear seawater, which is common within the mixed surface layer of the open ocean. Most related publications focus on extreme light fluctuations near the surface down to
$10 \mathrm{~m}$ water depth only (e.g. You et al., 2010; Gernez et al., 2011). We additionally simulate the availability of downwelling irradiance and its fluctuations down to $100 \mathrm{~m}$ depth. Deep-water light fluctuations may be of particular importance for the radiative energy supply for deep chlorophyll $a$ maxima which often develop between 20 and $150 \mathrm{~m}$ depth (e.g. Cullen, 1982; Furuya, 1990; Zielinski et al., 2002). Our modeling results for the underwater light field are compared with radiometric measurements from open ocean studies and against the HydroLight radiative transfer code, to verify the suitability of our model.

\section{Methods}

\subsection{Field study}

Measurements have been carried out in 2009 on board the $\mathrm{R} / \mathrm{V}$ Polarstern during a north-south traverse of the tropical and subtropical Atlantic Ocean (El Naggar and Macke, 2010). The data sets here presented have been recorded during local noon time under direct sun and nearly clear sky conditions. Downwelling irradiance within the water column was measured with a Ramses-ACC-VIS radiometer with a spectral range of 320 to $950 \mathrm{~nm}$ (TriOS, Germany). $E_{\mathrm{d}}$ spectra were each sampled over a period of $2 \mathrm{~min}$ per depth level down to $45 \mathrm{~m}$ water depth (sensor integration times between 16 and $128 \mathrm{~ms}$, step sizes in depth $2,2.5$ and $5 \mathrm{~m}$ ). Thus, we obtained mean values of the light field and indication of the irradiance variance in the water column. Within these upper 45 m, CTD (SBE 911 lplus, Sea-Bird Electronics, USA) measurements showed well-mixed and non-stratified seawater with an approximate chlorophyll $a$ content of $0.1 \mathrm{mg} \mathrm{m}^{-3}$ $\left( \pm 0.02 \mathrm{mg} \mathrm{m}^{-3}\right)$. Suspended particles and colored dissolved organic matter (CDOM, also referred to as Gelbstoff) not related to the phytoplankton content were negligible. At one station (16 November 2009) we observed a well-pronounced deep chlorophyll maximum located from 60 to $75 \mathrm{~m}$ depth (in CTD measurements down to $200 \mathrm{~m}$ ). Registration of sea states with differentiation of wind-sea and swell has been accomplished by an on-board meteorologist via visual assessment (see Table 1 for details).

In addition to the radiometric measurements, a specially developed underwater camera system was utilized to film areal light patterns that are projected on a white screen at different water depths (not shown here, see Hieronymi and Macke (2010) and Hieronymi (2011) for details and results).

\subsection{Model description}

Light fluctuations in water originate from the geometrical superposition of individual light beams that are refracted at the wave surface. Depending on the inherent optical properties IOPs of the water body, solar radiation is scattered and absorbed, which leads to a spatial spreading and attenuation of the initial light beam. When modeling the focusing effect of 
Table 1. Environmental conditions at three measuring sites onboard the R/V Polarstern (cruise ANT-XXVI/1) with same inherent optical properties of the upper ocean mixed layer.

\begin{tabular}{lllll}
\hline Date & & 30 October 2009 & 3 November 2009 & 16 November 2009 \\
\hline Location & & $19^{\circ} 44{\mathrm{~N} 23^{\circ} \mathrm{W}}^{\circ}$ & $4^{\circ} 54{\mathrm{~N} 23^{\circ} \mathrm{W}}^{\circ}$ & $32^{\circ} 38 \mathrm{~S}^{\circ} 7 \mathrm{~W}$ \\
Sun zenith angle & {$\left[{ }^{\circ}\right]$} & 33.7 & 22.8 & 15.5 \\
$E_{\mathrm{d}}(490 \mathrm{~nm})$ at the surface & {$\left[\mathrm{mW} \mathrm{m}^{-2} \mathrm{~nm}^{-1}\right]$} & 1271 & 1397 & 1475 \\
Wind speed & {$\left[\mathrm{m} \mathrm{s}^{-1}\right]$} & 11.0 & 5.4 & 10.0 \\
Wind sea wave height & {$[\mathrm{m}]$} & 1.5 & 0.5 & 2.0 \\
Wind sea wave period & {$[\mathrm{s}]$} & 5.0 & 3.0 & 5.0 \\
Swell wave height & {$[\mathrm{m}]$} & 2.0 & 1.5 & 1.5 \\
Swell wave period & {$[\mathrm{s}]$} & 9.5 & 8.5 & 8.0 \\
\hline
\end{tabular}

Table 2. Inherent optical properties of the considered water body at $490 \mathrm{~nm}$ wavelength and with $0.1 \mathrm{mg} \mathrm{m}^{-3}$ chlorophyll $a$ concentration (Morel et al., 2007; Morel, 2009).

\begin{tabular}{llll}
\hline Absorption coefficient (total) & $a$ & {$\left[\mathrm{~m}^{-1}\right]$} & 0.0280 \\
\hline - of seawater & $a_{\mathrm{Sw}}$ & {$\left[\mathrm{m}^{-1}\right]$} & 0.0150 \\
- of particles & $a_{\mathrm{p}}$ & {$\left[\mathrm{m}^{-1}\right]$} & 0.0082 \\
- of CDOM & $a_{y}$ & {$\left[\mathrm{~m}^{-1}\right]$} & 0.0048 \\
\hline Scattering coefficient (total) & $b$ & {$\left[\mathrm{~m}^{-1}\right]$} & 0.0793 \\
\hline - of seawater & $b_{\mathrm{sw}}$ & {$\left[\mathrm{m}^{-1}\right]$} & 0.0030 \\
- of particles & $b_{\mathrm{p}}$ & {$\left[\mathrm{m}^{-1}\right]$} & 0.0763 \\
\hline Attenuation coefficient (total) & $c$ & {$\left[\mathrm{~m}^{-1}\right]$} & 0.1072 \\
\hline - due to particles & $c_{\mathrm{p}}$ & {$\left[\mathrm{m}^{-1}\right]$} & 0.0844 \\
\hline
\end{tabular}

surface waves, light beams and the entire spread pattern must be superposed with respect to a spatial allocation.

The radiative transfer in water is mostly simulated by means of the Monte Carlo method (e.g. Plass et al., 1975; Mobley et al., 1993; Deckert and Michael, 2006; D'Alimonte et al., 2010). The physical processes of scattering, absorption and surface reflection/transmission are simulated for a sufficiently large number of individual photons, which is relatively time-consuming. In our model, time-consuming MC simulations are decoupled from the relatively fast geometric ray tracing for light fluctuation analysis. Once the light beam enters the water body with a specific transmission angle, its propagation is always equal at steady IOPs. By means of our model, it is possible to compute the definite geometric pattern of underwater light fields below arbitrary waves, taking into account all direct and diffuse radiative fractions.

\subsubsection{Underlying data and boundary conditions}

The model input parameters are selected in such a manner that maximum light field variability can be achieved (Dera and Stramski, 1986; Walker, 1994; Gernez and Antoine,
2009). The radiative transfer simulations are carried out for monochromatic light at a wavelength of $490 \mathrm{~nm}$; in this spectral range the water itself is very transparent for light (Pope and Fry, 1997). The chlorophyll $a$ concentration Chl of the entire photic water column is chosen to be $0.1 \mathrm{mg} \mathrm{m}^{-3}$, corresponding to very clear and oligotrophic oceanic water that can be found over a wide range of the tropical and subtropical regions of the earth; indeed, the annual mean value of $\mathrm{Chl}$ for the deep global ocean amounts to $0.193 \mathrm{mg} \mathrm{m}^{-3}$ (Wang et al., 2005). Table 2 specifies the wavelength- and Chl-dependent IOPs of seawater that are taken from Morel et al. (2007) and Morel (2009), following the concept that optical properties in the upper ocean can be derived from the optical properties of seawater itself and from the chlorophyll $a$ content. This water is classified as Case 1 (Morel and Prieur, 1977; Gordon and Morel, 1983), whereas Case 2 refers to the water types with optically active particulate and dissolved matter, not corresponding to the phytoplankton concentration. The refractive index $n$ of seawater, which depends on the wavelength, temperature, and salinity, is set to 1.34 (Segelstein, 1981). We utilized Petzold's phase function that accounts for both molecular (water) scattering and scattering at average particles (Petzold, 1972). In this phase function, hydrosols and planktonic particles are treated to be undirected; although we must assume that under high sea conditions particles are affected by considerable hydrodynamic accelerations and thus align preferentially in the direction of the fluid flow, which essentially alters the light scattering properties of seawater (Marcos et al., 2011). Another point that is neglected for this study is inelastic Raman scattering. Especially for low $\mathrm{Chl}$, Raman emissions generally affect the radiance field. Nevertheless, at the relevant spectral band around $490 \mathrm{~nm}$ Raman scattering plays a minor role only (Morel et al., 2002). Scattering is regarded as perfectly elastic and polarization effects are not considered. Furthermore, neither whitecaps nor bubbles near the surface are regarded in the model. Both can have strong effects on light scattering at the air-water interface and within the upper water layer, their influence starting at moderate winds (about $5 \mathrm{~m} \mathrm{~s}^{-1}$ ) and further rising with increasing wind (Stramski and Tegowski, 
Table 3. Classification of the single wave types with details for corresponding model domains.

\begin{tabular}{lrlllll}
\hline Wave class & & 1 & 2 & 3 & 4 \\
\hline Description of wave class & & Small Ultra Gravity & Medium Ultra Gravity & Large Ultra Gravity & Ordinary Gravity & Ocean Waves \\
\hline Wave length & $L[\mathrm{~m}]$ & $0.025-0.1$ & $0.15-0.5$ & $0.6-1.4$ & $1.5-20$ \\
Wave period & $T[\mathrm{~s}]$ & $0.12-0.26$ & $0.31-0.57$ & $0.6-1.0$ & $1.0-3.6$ \\
Wave height & $H[\mathrm{~m}]$ & $0.0008-0.009$ & $0.0045-0.045$ & $0.018-0.126$ & $0.045-1.8$ \\
Wave steepness & $H / L[-]$ & $0.03,0.06,0.09$ & $0.03,0.06,0.09$ & $0.03,0.06,0.09$ & $0.03,0.06,0.09$ & $0.002-0.13$ \\
\hline Applied Method & & Ray tracing & Ray tracing & Monte Carlo & Monte Carlo & Monte Carlo \\
\hline Grid depth & $z[\mathrm{~m}]$ & 2 & 5 & 10 & 40 & 102 \\
Grid width & $x[\mathrm{~m}]$ & - & - & 5 & 20 & 100 \\
Vertical resolution & $d z[\mathrm{~m}]$ & 0.001 & 0.001 & 0.01 & 0.05 & 0.01 \\
Detector width & $d x[\mathrm{~m}]$ & 0.0025 & 0.0025 & 0.05 & 0.1 \\
\hline
\end{tabular}

2001; Zhang et al., 2006). Ignoring whitecaps, bubbles and also flow-induced preferred particle orientation is therefore expected to overestimate the intensity of light focusing under many natural conditions. But for the sake of model simplicity and a better intercomparison of the impact of different wind and wave regimes, we stick to these idealized conditions and note that the largest light variability discussed here should be regarded as an extreme.

\subsubsection{The sea surface}

Ocean surface waves are assumed to be long-crested waves. They are nearly two-dimensional and the crests appear very long in comparison to the wavelength. Because of this fact and because we are interested in large-scale and highresolution light fields beneath several hundred metre long wave trains and water depths down to $100 \mathrm{~m}$, we limit the radiative transfer model to a 2-D domain with a twodimensional description of the wavy surface. The 3-D effect might be of more relevance for simulations of irradiance fluctuations near the surface, where small-scale waves govern the variability (Nikolayev and Yakubenko, 1978b; Hieronymi and Macke, 2010). Such 3-D simulations are shown by You et al. (2010), where the size of the water surface patch was $2 \mathrm{~m} \times 2 \mathrm{~m}$ with depths under consideration of less than $3 \mathrm{~m}$.

The sea surface consists of a superposition of various waves with different size, orientation and origin. The corresponding subsurface irradiance field is subject to interferences of the single lensing systems, which disable the development of a clear and homogeneous irradiance pattern. In order to understand the principal structure of light fluctuations down the water column we first look at regular single waves and later at irregular wave trains.

In general, most wind-generated gravity waves have a steepness (wave height to length $H / L$ ) of about 0.03 to 0.06 . In rare events, the wave steepness exceeds 0.09 (theoretically up to 0.14 for deepwater); steeper waves break. The exact shape of the wave has a strong impact on the resulting light field. Up to now, sinusoidal waves were implemented in radiative transfer models to show the lensing effect of single waves (Schenck, 1957; Dera and Gordon, 1968; Nikolayev and Khulapov, 1976; Stramski and Dera, 1988; Zanefeld et al., 2001; Deckert and Michael, 2006; D'Alimonte et al., 2010). In fact, water waves can be described as sine curves for small amplitudes with $H / L$ of less than 0.006 . Steeper waves should be represented by means of Stokes wave theory of higher order. Substantial deviations occur in the shape, i.e. the wave crest is higher and sharper and the trough is flattened, and in the hydrodynamical behavior, e.g. the Stokes wave moves slightly faster than a small-amplitude wave. Based on the formulation of Kinsman (1965), the nonlinear elevation $\zeta$ of any gravity wave can be sufficiently described by means of Stokes theory of fourth order:

$$
\begin{aligned}
\zeta & =\zeta_{\mathrm{a}} \cos k x+\frac{1}{2} k \zeta_{\mathrm{a}}^{2}\left(1+\frac{17}{12} k^{2} \zeta_{\mathrm{a}}^{2}\right) \cos 2 k x \\
& +\frac{3}{8} k^{2} \zeta_{\mathrm{a}}^{3} \cos 3 k x+\frac{1}{3} k^{3} \zeta_{\mathrm{a}}^{4} \cos 4 k x,
\end{aligned}
$$

where $\zeta_{\mathrm{a}}$ is the amplitude, $k$ the wave number, and $k x$ the phase. The term $k \zeta_{\text {a }}$ stands for the wave steepness, too. The time rate of change of the spatial subsurface light field directly corresponds to the phase speed of the surface wave. Long water waves propagate faster than shorter ones (dispersion). In the first order approximation the water wavelength $L$ and the wave period $T$ are related by:

$L=\frac{g}{2 \pi} T^{2}$

in which $g$ is the acceleration of gravity (Airy theory for deepwater gravity waves).

The single waves under consideration are classified into five categories each with size adapted model grid dimensions (for details see Table 3). The smallest realized horizontal grid resolution $d x$ is $2.5 \mathrm{~mm}$, which corresponds to the diameter of fast irradiance sensors (Darecki et al., 2011); the sensor head diameter of the Ramses-ACC-VIS is $5 \mathrm{~mm}$. Capillary $(L<$ 
$1.73 \mathrm{~cm}$ ) and ultra-gravity waves with periods $T$ of less than $1 \mathrm{~s}$ are directly associated with local winds. In particular, capillary and small ultra-gravity (also referred to as gravitycapillary) waves in the wavelength range of 0.7 to $3 \mathrm{~cm}$ are most dependent on the wind speed (Jähne and Riemer, 1990). Wave classes four and five contain fully developed gravity waves that also arise from wind, but they are not necessarily associated with the local wind situation as waves propagate away from their area of origin. Wind waves with periods of more than $10 \mathrm{~s}$ are usually referred to as swell, although also wave systems with periods $>6 \mathrm{~s}$ are often called swell, if they are the aftereffect of a previous or distant wind field. Single waves with periods up to $11 \mathrm{~s}$ are considered, larger waves are irrelevant in terms of light field fluctuations. According to the ocean wave statistics by Hogben and Lumb (1967), $95 \%$ of all visually observed sea conditions in the tropics and still more than $90 \%$ globally (for all seasons, all directions, and all areas) are accumulated within wave category five.

A natural sea surface is described by the superposition of weighted harmonics from the energy density spectrum of the sea state. In terms of underwater light field modeling, the basic concept was already applied for example by Snyder and Dera (1970), Nikolayev et al. (1972), Yakubenko and Nikolayev (1977), Walker (1994), and You et al. (2010). We used sea wave spectra, where the long wave part (swell and windsea) were handled with a double-peaked spectrum according to Ochi and Hubble (1976), and where the short directly wind-driven waves are represented by means of the formulation by Elfouhaily et al. (1997). The input parameters for the wave spectra, consisting of wind speed, wave height and period of wind-sea and swell respectively, are given in Table 1. The resulting unidirectional irregular wave field has a Gaussian slope distribution with the same wind-dependent range of wave slopes as observed by Cox and Munk (1954). We do not consider small-scale surface irregularities, such as the short (capillary or gravity-capillary) waves that ride ahead of crests of longer gravity waves (e.g. Longuet-Higgins, 1963) with the subsequent skewness of the Cox-Munk slope distribution (Longuet-Higgins, 1982). Nevertheless, in the model all waves are represented with a horizontal resolution $d x$ of $0.1 \mathrm{~mm}$. The irregular water wave profiles are $500 \mathrm{~m}$ long and feature all wave characteristics from the applied spectrum, including the especially pronounced gravity-capillary waves at approximately $1.7 \mathrm{~cm}$ wavelength (peak of the short wave spectrum) whose steepness depend on the local wind (Elfouhaily et al., 1997).

At the open sea, vertical deflections of the sea surface can be large, e.g. the statistically expected maximum wave height of the observed sea states (Table 1, 30 October 2009) is almost $5 \mathrm{~m}$. However, most comparable models do not account for vertical wave deflections, i.e. the wave structure is regarded as chain of successive wave slopes located at the mean waterline (e.g. Deckert and Michael, 2006; Weber, 2010; You et al., 2010). Nevertheless, surface elevations themself may act as direct source of light fluctuations.
D'Alimonte et al. (2010) showed a first MC model where the corresponding wave amplitude itself is considered. In our model, the $z$-variant wave deflection is taken into account.

When the mixing of the upper ocean due to heating and cooling is less important than that due to the waves, then the ocean's mixed layer depth (MLD), can be predicted directly from the significant wave height $H_{\mathrm{S}}$ (defined as the mean height of the one third highest waves) and the peak period $T_{\mathrm{P}}$ of the wave spectrum (Babanin, 2006). Even swell waves have been suggested as a possible source of ocean mixing (Kantha, 2006). In the given examples (Table 1), the calculated wave-induced turbulence reaches down to around 50$60 \mathrm{~m}$ depth, which fits to the CTD observations. In case of more pronounced sea states (especially higher waves), the wave-induced MLD can be more than $100 \mathrm{~m}$ (Babanin, 2006). With regard to the bio-optical properties of this mixed layer, the depth at which the photosynthetic available radiation $P A R$ is reduced to $1 \%$ of its value at the surface (euphotic layer depth) is about $100 \mathrm{~m}$, assuming a uniform chlorophyll $a$ concentration of $0.1 \mathrm{mg} \mathrm{m}^{-3}$ (Morel, 1988). For this reason, we show wave-caused light field variability down to $100 \mathrm{~m}$ water depth. But one should keep in mind that bio-optical and physical properties of the sea strongly vary with season and region (e.g. Dickey et al., 1993; de Boyer Montegut et al., 2004).

\subsubsection{Radiative transfer model}

Two different model approaches are chosen to deal with the variety of dimension requirements, a Monte Carlo-based model for large-scale irradiance simulations and a simplified ray tracing model for small-scale near-surface conditions. Table 3 gives an overview about the utilized grid sizes and resolutions with respect to the applied methods. The resolution specifications apply accordingly to simulations of irregular wave fields (Sect. 3.3). The basic difference is that the MC-based method considers all direct and diffuse radiation in the water, while the alternative ray tracing model considers the direct light beam only.

\section{Monte Carlo model}

The MC procedure that we employ differs in some aspects from other models that have been recently in use (Deckert and Michael, 2006; D'Alimonte et al., 2010; You et al., 2010). There is neither distinction between absorption and scattering as in Kirk (1981), nor a further identification whether the scattering process is caused by water-molecular or particle scattering (Morel and Gentili, 1991). We do not apply the usual concept of photon weight reduction, where the statistical losses by absorption and scattering are assessed by means of the single scattering albedo $\omega_{0}=b / c$ (at the scattering position: $w_{\text {new }}=w_{\text {old }} \omega_{0}$ ). Instead, in our model the photon path length is determined by the scattering 
coefficient $b$ only, and not by the attenuation coefficient $c$, and the light is continuously attenuated along the propagation path, which only depends on the total absorption coefficient $a$. Numerically both concepts should give the same results. However, our approach provides a faster convergence of the irradiance pattern since each horizontal grid segment is used as an irradiance detector (e.g. in the $100 \mathrm{~m}$ wide $\times$ $100 \mathrm{~m}$ deep grid, we have $1000 \times 1000$ detectors). Our MC model simulates the radiative transfer inside the water body only. The model domain covers up to $100 \mathrm{~m}$ water depth and $100 \mathrm{~m}$ width, with light beam access at one single point at the top. In detail the model pursues the following procedure.

If we assume uniform IOPs of the entire water body, then a light beam which enters the surface at a single point should propagate at first always similarly, only depending on its initial in-water transmission angle and its intensity at the surface. The photon tracing starts directly below the surface (at the point $\left[\begin{array}{ll}0 & 0\end{array}\right]$ ), whereat all photons have the same initial angle that depends on the insolation angle and the slope of the discrete wave segment and that is determined by Snell's law.

The free path length $l_{\mathrm{S}}$ between two subsequent scattering events is determined by the selection of an equally distributed random number $R$ between 0 and 1 and the total scattering coefficient $b$ (Table 2) (Macke, 2000)

$l_{\mathrm{S}}=-\frac{1}{b} \log (R)$.

With the given IOPs parameterized by $\mathrm{Chl}=0.1 \mathrm{mg} \mathrm{m}^{-3}$, the mean scattering path length $l_{\mathrm{S}}$ is $12.6 \mathrm{~m}$.

At the scattering point, the light beam changes its propagating direction in accordance to the global scattering phase function $\beta_{p+w}$ (Morel et al., 2002), where particle (Petzold, 1972) and molecular (Rayleigh) scattering are considered. This is numerically implemented using the cumulative scattering distribution

$D(\psi)=2 \pi \int_{0}^{2 \pi} \beta_{p+w}(\psi) \sin (\psi) d \psi$,

where a random number between 0 and 1 defines the scattering angle $\psi$. In natural particle-containing waters, light is predominantly scattered into the forward direction.

The actual attenuation of light occurs along its distance covered, on the grounds that the light beam transits toward a scattering point through an absorbing medium. In our model this approach is realized by a continuous intensity reduction of the light beam characterized by the medium's absorption properties. The intensity of the light beam decays exponentially along the path

$I=I_{0} \exp \left(-a l_{z}\right)$,

with the initial intensity $I_{0}$ just after entering the water, the total absorption coefficient $a$ (Table 2), and the total so far covered distance $l_{z}$ with respect to the depth level $z$.
Within the water body, light can be scattered back to the water surface. At the water-to-air boundary, which is assumed to be flat here, partial and total reflection occur. According to Snell's law total internal reflection happens at nadir angles $\theta>48^{\circ}$ (at $490 \mathrm{~nm}$ ). In this case the photon remains in the system, otherwise a new photon is selected. Partial internal reflection is neglected, as it plays a minor role only (Mobley, 1994). Light can additionally leave the system at all other external grid boundaries (e.g. lateral $\pm 50 \mathrm{~m}$ and at $100 \mathrm{~m}$ depth), but never enter again. The model does not allow for periodic boundary conditions as this would violate the concept of the spatial irradiance pattern of a single beam. This is in contrast to other models where periodicity is intended, e.g. D'Alimonte et al. (2010). The model domain, in which the Monte Carlo calculations for a single beam irradiance pattern are conducted, has to be large enough to ensure that the horizontal losses due to domain-leaving photons are negligible. With the given model input values (Table 2), these losses at the side amount to less than $0.01 \%$ of the total downwelling irradiance per water depth compared to a model domain with $200 \mathrm{~m}$ width. The model size requirements and the conceptual error of our model concerning the downward scattering from the underside of the wave modulated sea surface are discussed in Hieronymi (2011).

The ray tracing procedure considers a maximum number of scattering events, $N_{\max }$. As long as the "photon package" does not leave the model domain, its way through the medium is traced up to this number. If the photon leaves the area, a new photon is selected. With the given IOPs (Table 2), $N_{\max }$ is selected to be 40 ; after travelling more than $500 \mathrm{~m}\left(N_{\max } \cdot \bar{l}_{\mathrm{s}}\right)$ through the water body on average the "light beam" does not contribute an important intensity anymore (Eq. 5). This approach is consistent with the weight threshold value of $10^{-6}$ which is often used (e.g. in Plass and Kattawar, 1972; Mobley, 1994; D'Alimonte et al., 2010).

The covered path of the light is known with respect to global coordinates. Thus, the intensity values can be allocated and summed up for each horizontal segment $x$ at a level $z$. Since the orientation of photon propagation is also known, it can be stated whether its energy contributes to down- or upwelling irradiances, respectively. In the end, the accumulated weights for each grid cell are normalized by the total number of photons that have entered the system. The outputs of the MC model are areal distributions of normalized fractions of down- and upward directed irradiances $\left(E_{\mathrm{d} x z}\right.$ and $\left.E_{\mathrm{u} x z}\right)$. If we add all gridded irradiances at a particular depth, we gain the total amount of diffuse (scattered) and direct (unscattered) irradiance at this depth. This value must be equal to the mean planar downward/upward irradiance $\left(\bar{E}_{\mathrm{d}}\right.$ and $\bar{E}_{\mathrm{u}}$, respectively) at this particular depth.

The basic idea of the introduced concept is to decouple the time-consuming MC simulations from relatively fast, geometric super-positioning of spatial light fields that arise from a deflected sea surface. In order to achieve this, we carried out MC simulations for different ray tracing starting angles 
between $0^{\circ}$ and $70^{\circ}$ (downward directed) with an angular spacing of $0.05^{\circ}$ to $1^{\circ}$, each with $2 \times 10^{5}$ photons. The corresponding grid size specifications depend on the considered wave size and are given in Table 3 (wave class 3 to 5). All 2-D irradiance grids that result from a single beam photon entry are stored in a database, which then provides a basis for the wave focusing analysis.

\section{Diffuse sky radiation}

The total irradiation that enters the water accounts for the direct solar radiation (with zenith angle) and diffuse skylight from atmospheric Rayleigh and Mie scattering. The fraction of diffuse irradiation depends (amongst other things) on the wavelength, the sun position, cloudiness, and aerosol load (Walker, 1994). For example, an overcast sky with no visible sun is completely diffuse, whereas the ratio of background sky irradiance to total irradiance can be approximately $10 \%$ under very clear sky conditions with a high sun elevation at $490 \mathrm{~nm}$ wavelength. The distribution of incident angles and the amount of the sky radiance can be computed for example with the model by Zibordi and Voss (1989). In case of a clear sunny atmosphere, the angular distribution of atmospheric diffuse light is close to isotropic (same assumption as in You et al., 2010 and D' Alimonte et al., 2010).

Based on the database with $E_{\mathrm{d} x z}$ fields of single beams, the following points are considered to generate a wave slopedependent $E_{\mathrm{d} x z}$ field for diffuse skylight: (1) the incidence of diffuse radiation is assumed to be isotropic. (2) the halfspace above the surface is partly shadowed in case of an inclined wave segment. (3) the effective transmission angle of each irradiation part is determined via Snell's law, and (4) the transmission rate of each single portion is calculated from Fresnel's equations.

Figure 1 shows the downwelling irradiance field for clear sky conditions with $10 \%$ diffuse irradiation and $90 \%$ direct sun light from $0^{\circ}$ zenith angle. The color scale is set logarithmic to resolve the orders of magnitudes of $E_{\mathrm{d} x z}$. The distribution shows a well-defined light cone of about $96^{\circ}$ width that is due to the diffuse irradiation and which is associated with Snell's window. Nevertheless, most radiative parts are located near to the initial path of the direct sun, e.g. $50 \%$ of the total distributed irradiance in the field is accumulated within the $1 \mathrm{~m}$ wide water column at $x=0$.

\section{Superposition of individual light fields}

The underwater light field considers all direct and diffuse fractions of the downward directed irradiance with respect to the exact point of insolation at the surface. To compute this, we firstly initialize an overall grid system (with global coordinates $\mathrm{x}$ and $\mathrm{z}$ ) and dimensions of the area of interest, e.g. in case of irregular wave profiles, the field is $500 \mathrm{~m}$ wide and more than $100 \mathrm{~m}$ deep with a discretization of $0.1 \mathrm{~m}$ in

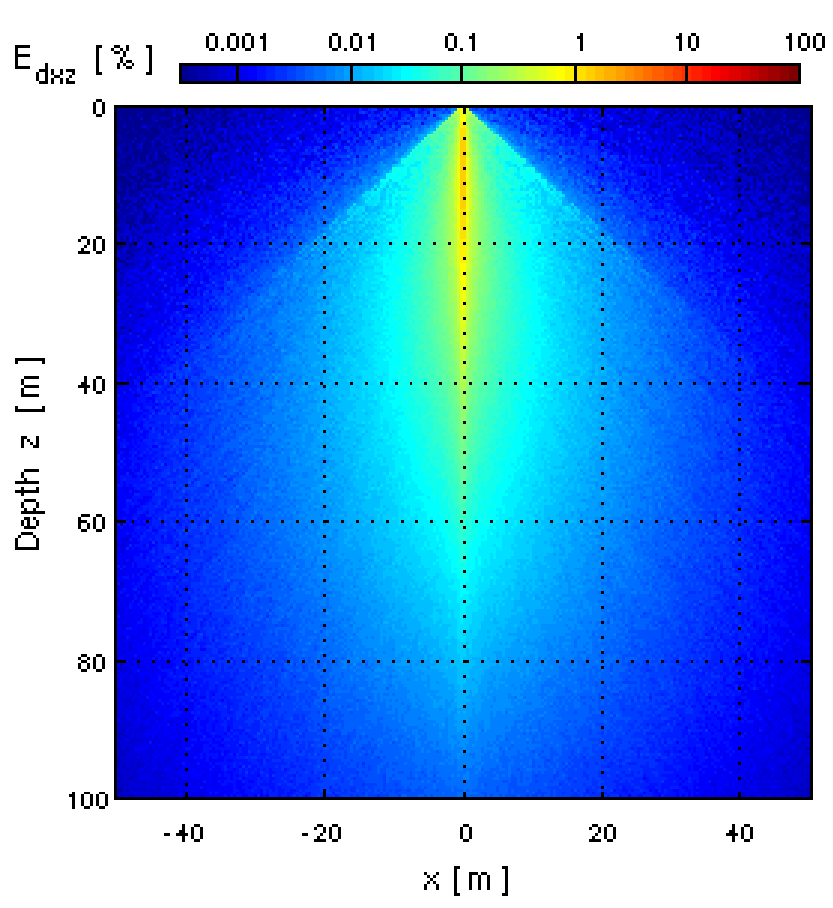

Fig. 1. Spatial expansion of light, in terms of the downwelling irradiance $E_{\mathrm{d}}$, within the water column due to $90 \%$ direct solar irradiation (zenith angle $0^{\circ}$ ), $10 \%$ isotropic diffuse skylight and a non-tilted wave facet (logarithmic color scale).

each direction. Then, the $500 \mathrm{~m}$ long wave profile has to be located in the global grid. Now, for each horizontal wave segment a vertical position of light incidence with corresponding wave slope can be allocated. In the next step the global in-water transmission angles and rates are determined via Snell's law and the Fresnel equations using the relative sun position and the wave slope. Now the total light incidence per $10 \mathrm{~cm}$ grid segment at the surface has to be determined. Here, for every wave facet of $0.1 \mathrm{~mm}$ width the corresponding $100 \mathrm{~m} \times 100 \mathrm{~m} E_{\mathrm{d} x z}$ fields for the single beam and for the diffuse skylight are taken from the database and weighted according to the transmission rate and the ratio of directto-diffuse insolation. The complete $100 \mathrm{~m} \times 100 \mathrm{~m}$ field that arises from a $10 \mathrm{~cm}$ wide light incidence at the surface must now be adapted to the global coordinate system by taking into account the current surface deflection. Overlapping parts of the individual light fields above the water surface are cut off and are not further considered, just as internal reflections that would occur at a wave-shaped surface; now internal reflection is treated as it would be at a flat surface. Both aspects cause negligibly small errors in the determination of the underwater light field only (Hieronymi, 2011).

The statistical evaluation of the subsurface $E_{\mathrm{d} x z}$ field refers to the $400 \mathrm{~m}$ wide area in the center only, which includes all diffuse radiation that was inserted within the $500 \mathrm{~m}$ wave profile. The vertical length of the water column between the actual surface elevation and a detector is defined 
as reference or true depth $z_{\mathrm{t}}$. In the following all radiative data refer to this reference depth, so that the depth contours (of same hydrostatic pressure) are always shaped as the water surface. The reference depth is handled differently in other publications e.g. in D'Alimonte et al. (2010). The authors refer to a depth displaying the surface wave effects on the pressure gauge and therefore to virtual isobars. This approach makes sense but it is based on linear wave theory, which makes an adaptation onto nonlinear wave systems intricate.

In the discussed case with an irregular wave, we effectively consider $2 \times 10^{5}$ photons per $0.1 \mathrm{~mm}$ wave segment over a range of $500 \mathrm{~m}$; this amounts to a total of $10^{12}$ (one trillion) photons. Sensitivity studies have shown that larger numbers of photons do not yield significantly different results.

Light fluctuations are characterized by parameters, which are normally based on temporal changes of the light field, i.e. measured time series of $E_{\mathrm{d}}$. This work considers spatial differences. This essentially is the same since both quantities are related by the dispersion equation Eq. (2). The horizontal averaging of all $E_{\mathrm{d} x z}$ values at a depth $z_{\mathrm{t}}$ is equal to the total downwelling irradiance $\bar{E}_{\mathrm{d}}$, which always decreases exponentially with water depth. $E_{\mathrm{d}}$ fluctuations are commonly described by the coefficient of variation

$C V=\frac{\sigma_{E}}{\bar{E}_{\mathrm{d}}}$,

given as the ratio of the standard deviation $\sigma_{E}$ and the mean downwelling irradiance at the reference depth. $E_{\mathrm{d}}$ time series are typically normalized, in order to evaluate extreme values and the distribution of occurrence probability (You et al., 2010; Gernez et al., 2011). The normalized downwelling irradiance, in relation to spatial $E_{\mathrm{d}}$ variability, is denoted as

$\chi=\frac{E_{\mathrm{d} x z}}{\bar{E}_{\mathrm{d}}}$.

It basically describes the multiple of an $E_{\mathrm{d} x z}$ value compared to the mean irradiance at a depth. Dera and Stramski (1986) defined irradiance pulses that exceed the mean irradiance by a factor (here $\chi$ ) of more than 1.5 as underwater light flashes.

\section{Alternative ray tracing model}

The top $10 \mathrm{~m}$ of the water column are of particular importance in terms of wave-induced light fluctuations, since here light flashes are generally most pronounced and most frequent. Especially in clear ocean water the fraction of scattered light in the total $E_{\mathrm{d}}$ is small in the first metres compared to the direct light beam. Furthermore, most of the scattered light is located very close to the initial propagation direction, because of the predominance of forward scattering. Under these assumptions it is reasonable to only consider the direct beam and to neglect all scattered light.

The fundamental simplification is the utilization of the ray tracing procedure as for example used in Schenck (1957)

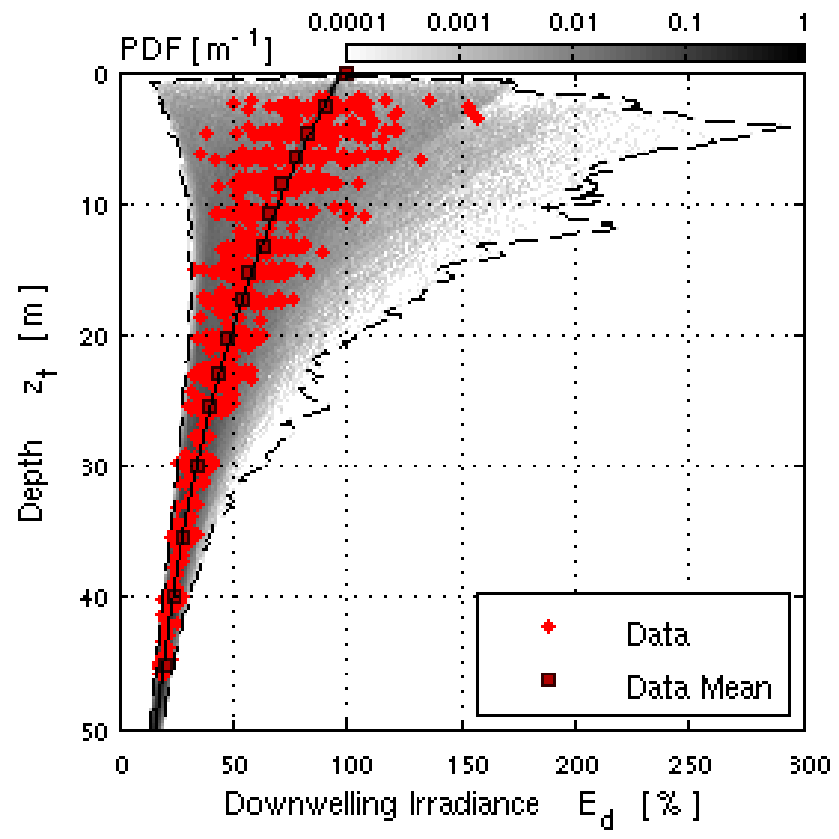

Fig. 2. Comparison of downwelling irradiance $E_{\mathrm{d}}$ as calculated by the model (for $490 \mathrm{~nm}$ ) vs. offshore measurements with the spectral radiometer at $489 \mathrm{~nm}$ (30 October 2009); data points in red with squares for the corresponding mean values, the modeled $P D F$ with $d x=10 \mathrm{~cm}$ is gray shaded with dashed outlines.

or more recently by Zaneveld et al. (2001) and an additional continuous attenuation of the individual rays by BeerLambert's law Eq. (5) (based on the absorption coefficient in our formulation). The contribution of all accumulated rays in a detector field provides an adequate estimate of the downwelling irradiance. Without major accuracy losses, this method is applicable for clear seawater (with the given IOPs) and down to depths of about $5 \mathrm{~m}$ (Hieronymi, 2011). This method is computationally more efficient (faster) and allows for high spatial resolution with $d x=2.5 \mathrm{~mm}$, i.e. highfrequency analysis.

\section{Results and discussion}

\subsection{Benchmark tests of the model}

Model results are compared with data from field measurements (Sect. 2.1) and with the widely used HydroLight radiative transfer software by Mobley (1994) using the invariant embedding method. Figure 2 shows one example of measurements (red dots), with corresponding $E_{\mathrm{d}}$ mean values within $\pm 0.3 \mathrm{~m}$ depth range (red squares). The probability density function $P D F$ of simulated $E_{\mathrm{d}}$ is gray shaded with dashed outlines. The solid line represents the total plane downwelling irradiance $\bar{E}_{\mathrm{d}}(d x=10 \mathrm{~cm}$ model $)$. All measured data are within the range of highest expected occurrence probability; in none of the cases under consideration 

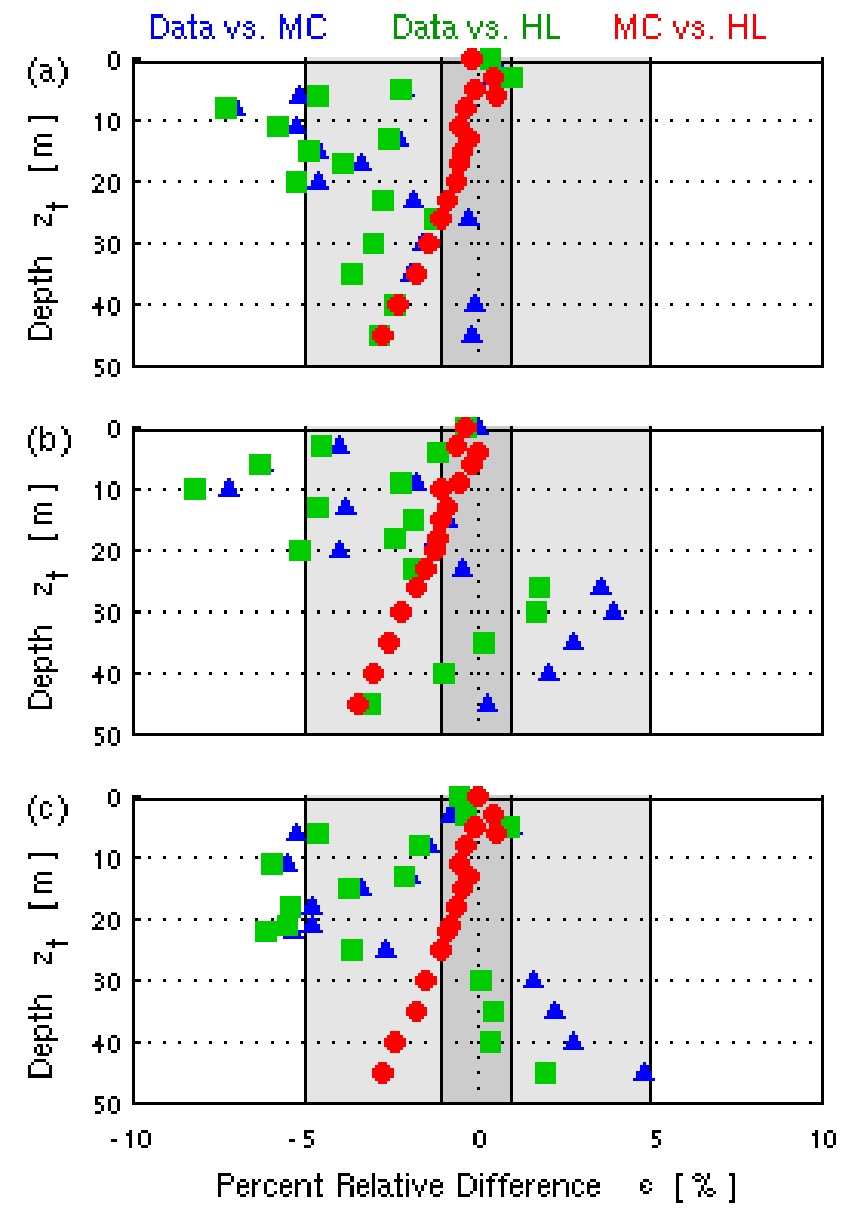

Fig. 3. Percent relative differences of $E_{\mathrm{d}}$ mean values between measured data, our Monte Carlo (MC) model and HydroLight (HL); (a) 30 October 2009; (b) 3 November 2009; (c) 16 November 2009, the related conditions are specified in Table 1.

data points lie outside the predicted $P D F$ limits. In the shown example, light flashes $(\chi>1.5)$ were registered down to $11 \mathrm{~m}$. The deepest occurrence of light flashes has been observed at $20.8 \mathrm{~m}$ depth at another day of the cruise with similar lighting conditions, which is the greatest depth of observed light flash occurrence as far as we know. According to the model, light flashes could be found even in $35 \mathrm{~m}$ water depth. Our measurements were not sufficient to show the high-frequency variance that is predicted by the model, the sampling rate and integration time of the used radiometer do not permit high-frequency sampling. However, the high $E_{\mathrm{d}}$ variance near the surface is well documented (e.g. Gernez et al., 2011). The validation of our modeled irradiance distribution, especially at clear seawater, fully developed seas and particularly below the top $10 \mathrm{~m}$ layer, is a task for specialized radiometric sensors as the novel system by Darecki et al. (2011).

The mean values of the measured data can be compared to the $E_{\mathrm{d}}$ mean of our Monte Carlo (MC) simulations and equivalent HydroLight (HL) runs with the same wavelength, refractive index of water, sun zenith angle, surface insolation, wind speed, IOPs, scattering phase function, and with the same sky diffuseness. Figure 3 compares the percent relative difference

$\varepsilon=100 \frac{\bar{E}_{\mathrm{a}} \bar{E}_{\mathrm{b}}}{\bar{E}_{\mathrm{b}}}$

of mean values of measured data vs. MC (blue triangles), data vs. HL (green squares), and MC vs. HL (red dots), respectively. The commonly considered uncertainty threshold for in-situ radiometric measurements is $5 \%$ (light gray shaded); according to the manufacturer (TriOS, Germany) the detection accuracy of our irradiance sensor is better than 6-10\% (depending on spectral range). Comparisons of radiative transfer computations result in lower uncertainties, typically within less than $1 \%$ (dark gray shaded). Figure 3 shows the comparisons for the three stations whose quite similar environmental conditions are specified in Table 1. Typically the averaging over about 80 data points $(2 \mathrm{~min}$ each) yields unsteady means, especially in the upper $25 \mathrm{~m}$, where the $E_{\mathrm{d}}$ variance is high. In general, the overall agreement between averaged observations and the modeling results (MC and HL) is satisfying. The agreement between our MC model and HydroLight is very good within the top $25 \mathrm{~m}$. Our model tends to overestimate the total light attenuation compared to HL; the bias continuously grows to less than $20 \%$ in $100 \mathrm{~m}$ depth. These differences, which are still comparable with those of previous model benchmarking (e.g. Mobley et al., 1993; D'Alimonte et al., 2010), can be explained by inherent differences of the applied methods, regarding for example the representation of the diffuse sky light (HL uses an idealized sky model) or the scattering properties of the water (we use a higher interpolated scattering angle discretization, which could affect the scattering pattern and in particular the forward scattering). Another source for deviations is the different sea surface representation. HydroLight employs the wind-depending Cox-Munk wave slope statistics. Our continuous wave profile accounts for the same local wind conditions but also for a fully developed sea state; its slope distribution resembles a Cox-Munk distribution with actually more wind (the PDF skewness is not considered). Thus, more light is scattered directly at the rougher surface and $\bar{E}_{\mathrm{d}}$ becomes slightly smaller. Furthermore, the summation of lateral losses of diffuse radiation (beyond the $\pm 50 \mathrm{~m}$ from the photon entry) is another reason for the underestimated total $E_{\mathrm{d}}$ compared to HL especially in greater depths. The lateral losses are small $(<0.01 \%$ per depth $)$ at perpendicular irradiation; a little more escapes at the edges in case of a strongly inclined wave slopes, which occurs more frequently at strong wind. However, by far the most radiation is very close to the direct initial light beam (within $\pm 10 \mathrm{~m}$ ), whose direction is determined by the wave slope, even in $100 \mathrm{~m}$ depth (see Fig. 1). It is primarily the narrow light beam that causes the reported irradiance variability at depths. 


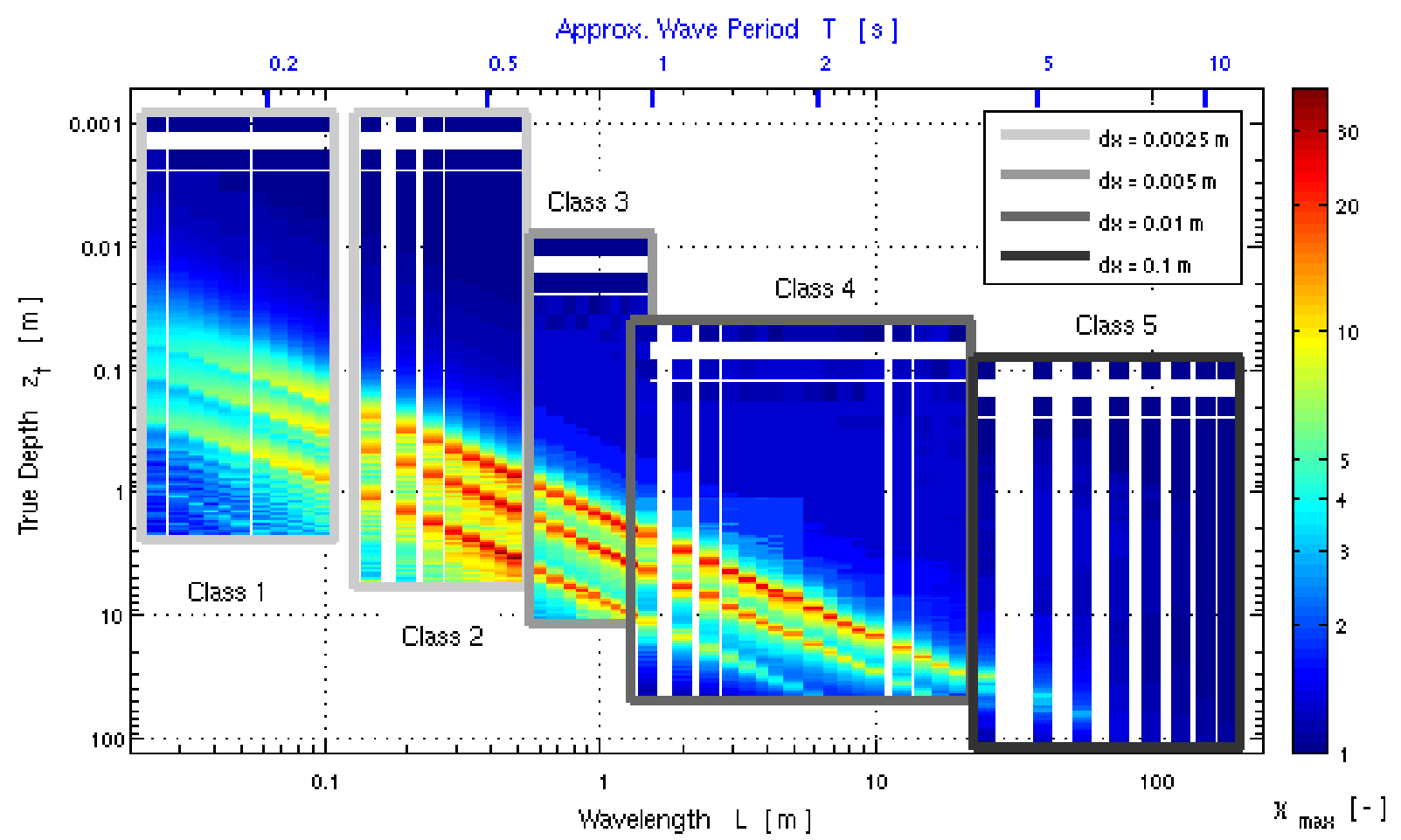

Fig. 4. Maximum possible normalized downwelling irradiance $\chi_{\max }$ due to single waves per water depth $z_{\mathrm{t}}$ and in accordance with the surface wavelength $L$ (and period $T$ at the top); the five framed wave classes refer to different detector sizes $d x$ (note the logarithmic color scale).

\subsection{Downwelling irradiance fields below single waves}

Water waves do not represent perfect lenses and therefore do not form perfect focal points. There is always some degree of distortion or spherical aberration introduced by the wave, which is further amplified by the nonlinear wave shape. Subsurface $E_{\mathrm{d} x z}$ distributions subject to about 300 regular single waves with sizes between $2.5 \mathrm{~cm}$ and $200 \mathrm{~m}$ were analyzed. The essence of all single wave simulations is assembled in Fig. 4. The color mapping indicates the maximum normalized downwelling irradiance $\chi_{\max }$ that is possible at the given wavelengths and at the three wave steepnesses under consideration. The wave period $T$ corresponds to the light fluctuation period according to Eq. (2). The wave classes 1 to 5 are framed to underline the changing detector sizes $d x$. Three diagonal lines of irradiance enhancement are clearly visible. They correspond to the focal points at the particular wavelengths where the upper line corresponds to the steepest waves with $H / L=0.09$, the middle line stands for 0.06 , and the lower line for flat waves with 0.03 . Remember that most wind waves have a steepness between 0.03 and 0.06 . Especially at class 1, regular waves can build up deeper-lying focal points of higher order caused by neighboring waves. Their irradiance enhancements are also visible but less well pronounced. The figure basically shows the range of impact for certain waves types. For example, the most intense light fluctuations at $1 \mathrm{~m}$ depth (with $E_{\mathrm{d}}$ maxima of more than $500 \%$ ) mainly arise from waves with lengths of $10 \mathrm{~cm}$ to $1 \mathrm{~m}$ (ultra-gravity waves), whereas at $10 \mathrm{~m}$ depth waves of 1 to $10 \mathrm{~m}$ length cause strongest fluctuations (ordinary gravity waves). For the first three wave classes flatter waves develop more intensive and deeper irradiance pulses at a given wavelength. Capillary waves $(L<1.73 \mathrm{~cm})$ can produce light flashes close to the surface, but they do not directly cause the most intense light fluctuations (also observed by Stramski and Dera, 1988). The strength of enhancements at the focal points clearly decreases at the left hand side of the figure. More relevant are the well pronounced narrow light rays that follow from such very small waves. Those rays are clustered somewhat deeper due to longer waves see Fig. 5a. It becomes obvious that the longer the wave is the deeper is its potential impact. Even $200 \mathrm{~m}$ long swell waves can theoretically develop an enhancement of $15 \%$ below $90 \mathrm{~m}$ of water depth; the coefficient of variation $C V$ can be up to $6 \%$. We suggest that this $E_{\mathrm{d}}$ variability could be of ecological significance, especially in the deep light limited zone. Note that only selected wavelengths are studied. The white vertical stripes represent information gaps at wavelengths in between.

Dera and Gordon (1968) presented a sine-wave-based approximation of the focal length, which gives good agreement for flat waves with $H / L=0.03$ up to wavelengths of $5 \mathrm{~m}$. 
At steeper waves nonlinearity effects of the shape become noticeable; the focal length is estimated to be considerably deeper. On the basis of our simulations for single waves, the water depth $z_{\mathrm{f}}$ of maximum radiative enhancement $\chi_{\max }$ fits to following parameterization:

$z_{\mathrm{f}}=\left[1600(H / L)^{2}-274(H / L)+13\right] L$,

which is valid for depths down to approximately $30 \mathrm{~m}$ for all wave steepnesses (wavelength $L$ ranges from $0.1 \mathrm{~m}$ to 5 , 15 , and $25 \mathrm{~m}$ for $H / L=0.03,0.06$, and 0.09 , respectively). Larger waves do not necessarily accumulate most radiation within the focal point, since light beams are attenuated and scattered with increasing depth. Thus, the depth of maximum enhancement shifts upwards to the surface.

The magnitude of an irradiance pulse depends on the detector size $d x$ and the sampling rate, e.g. a $10 \mathrm{~cm}$ wide sensor below a $10 \mathrm{~cm}$ long wave cannot resolve any enhancement; it only measures the mean value at that depth. For the present study we make use of four different horizontal grid sizes $d x$ which basically depend on the deployment depth, or rather reflect the extent of radiometer integration time. The effects of the sensor diameter on irradiance measurements and depth resolution requirements for optical profiling are discussed by Darecki et al. (2011) and Zibordi et al. (2004). Maximum possible radiative enhancements are associated with the steepest waves $(H / L=0.09)$; nevertheless, flatter waves are much more likely. An irradiance pulse can theoretically exceed the mean irradiance by a factor of 40 at a water depth of $1 \mathrm{~m}$ with respect to a $2.5 \mathrm{~mm}$ sensor. The corresponding wave that causes the light pulse is $80 \mathrm{~cm}$ long. The greatest possible depth of light flashes $(\chi=1.5)$ is at approximately $80 \mathrm{~m}$, and this is caused by a more than $60 \mathrm{~m}$ long gravity wave ( $T=6 \mathrm{~s}, H=5.5 \mathrm{~m}$, and thus extremely rare occurrence probability).

Certainly, these data result from perfect laboratory waves. Superposition effects of different sized waves are important, since the overlaying restricts the ability of waves to form such efficient lensing systems. Nevertheless, near the surface comparable extreme values have been measured (Gernez et al., 2011; Darecki et al., 2011).

\subsection{Light fields below irregular waves}

Distributions of downwelling irradiance below irregular wave profiles are shown in Fig. 5. The light fields were simulated using three model domains with different resolutions. First, we discuss the high-resolution ray tracing model with $2.5 \mathrm{~mm}$ detector size that covers an area of approximately $20 \mathrm{~m} \times 5 \mathrm{~m}$ to study near surface fluctuations (Fig. 5a and b). Figure $5 \mathrm{c}$ refers to a model domain of $150 \mathrm{~m} \times 40 \mathrm{~m}$ with $1 \mathrm{~cm}$ resolution (based on the superposition of MC calculated single beam light fields). The third MC-based model covers an area of $400 \mathrm{~m}$ horizontal extent and $100 \mathrm{~m}$ depth with $d x=10 \mathrm{~cm}$ (Fig. 5d). The color coding in the figure is
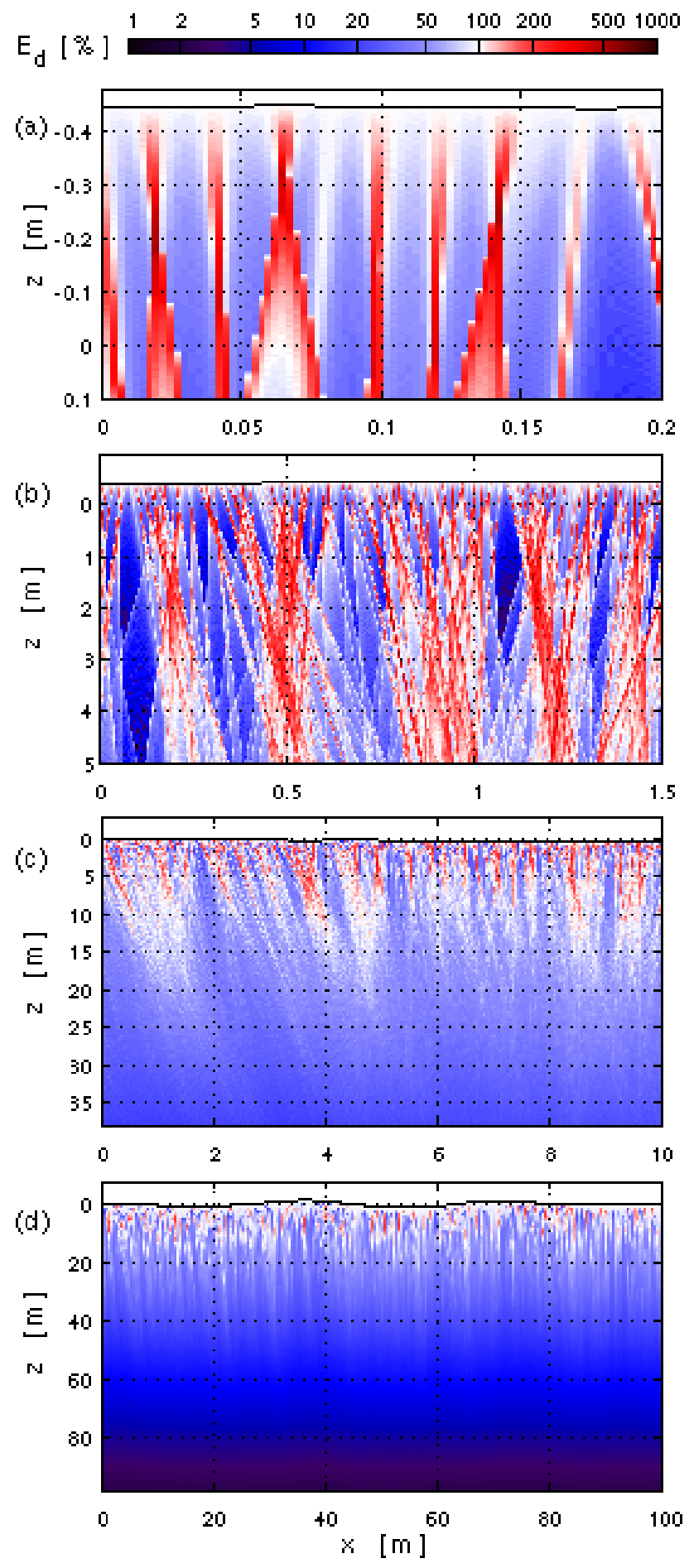

Fig. 5. Downwelling irradiance distributions beneath an irregular wave profile according to the conditions on 30 October 2009; (a) and (b) details from the near-surface model with $d x=2.5 \mathrm{~mm}$ resolution; (c) $d x=1 \mathrm{~cm}$; (d) model resolution $10 \mathrm{~cm}$ (logarithmic color scale). 
logarithmic again with red colors for $E_{\mathrm{d}}>100 \%$ and bluish for decreasing values.

With regards to the fine structure of the sea surface, local wind in particular affects the height and thus steepness of gravity-capillary waves. The wave spectrum has a highfrequency peak at $1.7 \mathrm{~cm}$ wavelength and it features a clear saturation of the curvature spectrum for high wind speeds (Elfouhaily et al., 1997). Those gravity-capillary waves build up clear single stripes of $E_{\mathrm{d}}$ enhancements shown in red with focal points in depths between 10 and $50 \mathrm{~cm}$ (Fig. 5a). Overlaying medium-size ultra-gravity waves (Table 3 ), which are already much less dependent on the wind speed (Jähne and Riemer, 1990), further deflect these single rays. This leads to intensified light beam grouping at true depths of 1 to $4 \mathrm{~m}$ (Fig. 5b). Together with the occurrence of secondary and further focal points that are caused by neighboring gravitycapillary waves, those larger waves are responsible for very intense fluctuations and extreme irradiance peaks within the top $5 \mathrm{~m}$ layer. With increasing depth the gravity-capillary wave influence wears away (Fig. $5 \mathrm{c}$ and d); the pronounced enhancement stripes are geometrically scattered, beam focusing is reduced, and in addition the light intensity is attenuated. Image analysis of spatial underwater light fields confirms the increasing blurring of small-scale structures (Hieronymi and Macke, 2010). Under the assumption that capillary and gravity-capillary waves of 0.7 to $3 \mathrm{~cm}$ length are most dependent on wind friction velocity (Jähne and Riemer, 1990) we deduce that the influence of local wind on $E_{\mathrm{d}}$ fluctuations is restricted approximately to the upper $10 \mathrm{~m}$ of the water column. Below this layer, light variability is obviously driven by longer and thus more developed waves. During our offshore measurements, we had mainly swell dominant sea states (in terms of the relative ratio of energy associated to each wave system), which is in accordance with the relevant wave climatology (Hogben and Lumb, 1967; Sterl and Caires, 2005). This is an interesting point since the appearance of swells may imply strong sea surface deflections, even in the absence of local wind. However, since the small-scale geometric roughness of the sea surface efficiently scatters light, the potential lensing effect of larger waves is reduced too. Generally, the wind-roughened surface affects the mean state of the light regime within the whole lit water column, which is taken into account in most radiative transfer models as for example in HydroLight (Mobley, 1994).

The depth-dependence of $\chi$ is illustrated in Fig. 6, where the corresponding wave profile is additionally marked (note: depth $z$ and the wave amplitude $\zeta$ are positive downward). The top panel (Fig. 6a) shows the irradiance variability at $1 \mathrm{~m}$ water depth. The run of the curve is similar to observed irradiance time records as for example reported by Dera and Stramski (1986) or You et al. (2010). The irradiance variability is high and extreme irradiance pulses can exceed the mean irradiance by a factor of 8 . The direct attribution of the wave shape is not distinguishable in this case. The second panel (Fig. 6b) shows $\chi$ at $20 \mathrm{~m}$. Here $\bar{E}_{\mathrm{d}}$ is decreased to
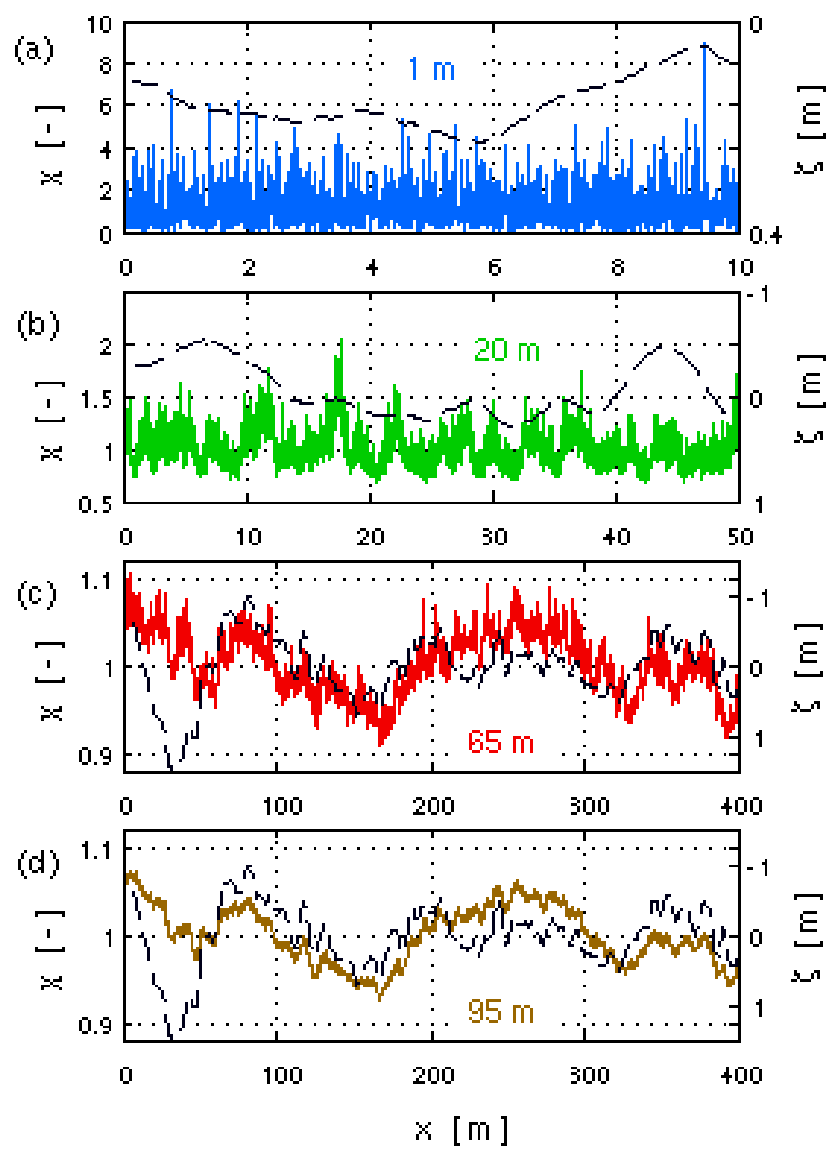

Fig. 6. Normalized downwelling irradiance $\chi$ at four different water depths with (a) $2.5 \mathrm{~mm}$, (b) $1 \mathrm{~cm}$, and (c) and (d) $10 \mathrm{~cm}$ horizontal grid resolution; on the right ordinate (dashed) is the corresponding surface elevation (30 October 2009).

about $50 \%$ of the initial surface value; but occasionally, irradiance peaks can reach $100 \%$ (enhancement factor $\chi=2$ ). The distances between light flashes $(\chi=1.5)$ are between 2 and $10 \mathrm{~m}$. With Eq. (2) this corresponds to dominant light fluctuation periods of 1.1 to $2.5 \mathrm{~s}$. This again is consistent with observations at this depth and at the same wind speed (of $11 \mathrm{~m} \mathrm{~s}^{-1}$ ) (Hieronymi and Macke, 2010). The corresponding wave structure in Fig. $6 \mathrm{~b}$ is not clearly mirrored in the radiative profile at that depth. Deep chlorophyll maxima are often observed at depths of $65 \mathrm{~m}$ and more (Furuya, 1990). Figure 6c shows that here intensity peaks and also irradiance minima differ by only $10 \%$ from the mean $\left(E_{\mathrm{d}}\right.$ varies between 7.8 and $9.7 \%$ ), and that radiative fluctuations evidently reflect the large-scale surface structure. In $95 \mathrm{~m}$ (Fig. 6d) the $\chi$-profile is even more smoothed on the small scale and adapted to the long gravity waves. However, the impact of fully developed ocean waves is evident.

Figure 7 shows the associated spectral information of the $\chi$-profiles from Fig. 6 . The power spectral density of light fluctuations is computed using fast Fourier transformation. 


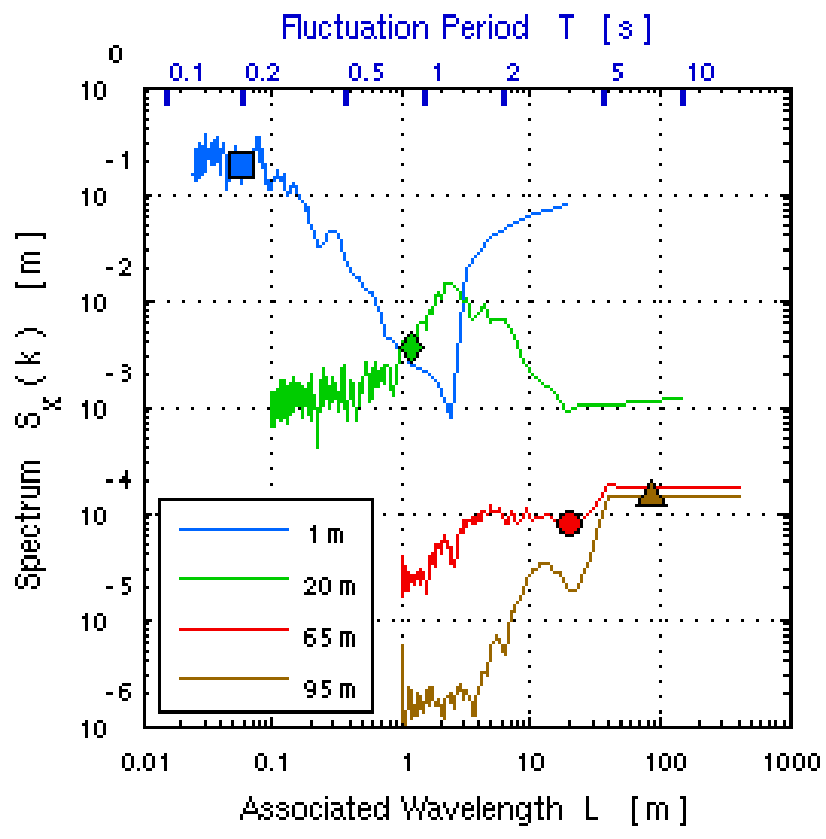

Fig. 7. Power spectral density of the four normalized irradiance profiles from Fig. 6; the mean fluctuation lengths $L_{\mathrm{m}}$ are additionally marked (30 October 2009).

The spectra show the characteristic range of corresponding water wavelengths and periods. The different magnitudes of the spectra in Fig. 7 show the strength of variance at a certain waveband that in total decreases with depth, i.e. the fluctuation amplitudes are very small at $95 \mathrm{~m}$ depth compared to depths near the surface. The maxima of the spectra indicate the predominant distance between two subsequent $E_{\mathrm{d}}$ peaks, e.g. the mean peak wavelength $L_{\mathrm{p}}$ at $20 \mathrm{~m}$ depth is $2.4 \mathrm{~m}$, which corresponds to an average fluctuation period of $1.25 \mathrm{~s}$. In Fig. 7, the mean fluctuation lengths $L_{\mathrm{m}}$ are additionally marked. This is the spectral center of gravity, which indicates the average wavelength (distance) of all fluctuations. In general, mean fluctuation length and period increase with increasing depth. Within the top $5 \mathrm{~m}$, ultra-gravity waves dominate the light fluctuations. At $100 \mathrm{~m}$ depth, fluctuations have adapted to the low-frequency part of the sea spectrum, which complies with swell waves in the given example. The increasing adaptation of light fluctuation periodicity with water depth to the dominant wave of a sea state was also observed within the top $20 \mathrm{~m}$ by Nikolayev and Yakubenko (1978a), Fraser et al. (1980), and Wijesekera et al. (2005).

Statistical evaluations of the light field simulations are summarized in Fig. 8. The probability density functions $P D F$ show similar features as records by You et al. (2010) or Gernez et al. (2011) but with much higher depth discretization $(d z=1 \mathrm{~cm}, 5 \mathrm{~cm}$, and $10 \mathrm{~cm})$. In the high-resolution model (Fig. 8 top) the fluctuation maximum is located between $25 \mathrm{~cm}$ and $1 \mathrm{~m}$ depth, which must be associated with waves of $4 \mathrm{~cm}$ to $1 \mathrm{~m}$ length (ultra-gravity waves). With $d x=1 \mathrm{~cm}$, the $P D F$ maximum is at a depth of approximately $1 \mathrm{~m}$, while in the model with $d x=10 \mathrm{~cm}$ the fluctuation maximum occurs near $5 \mathrm{~m}$. Thus, the approximation of the fluctuation maximum depends on the spatial or temporal resolution. The general trend of the probability functions of all model sizes is plausible: initially the fluctuation amplitudes characteristically increase, then decrease gradually with depth (Snyder and Dera, 1970), and in the same way the level-mean irradiance decreases exponentially. Obviously, the correct choice of model size and resolution depends on the depth of interest. Near the surface irradiance fluctuations must be recorded with a high spatial resolution of $d x=2.5 \mathrm{~mm}$ and a correspondingly high temporal resolution. The model with detector width of $1 \mathrm{~cm}$ provides reasonable information down to about $30 \mathrm{~m}$. For depths of interest beyond $20 \mathrm{~m}$ the $10 \mathrm{~cm}$ model resolution is sufficient.

The occurrence of radiative enhancements is quantified by means of a threshold analysis of the normalized downwelling irradiance profiles (Dera and Stramski, 1986; You et al., 2010). By counting the number of fluctuation amplitudes that exceed the various flash threshold levels $\chi_{\text {th }}$, we obtain the frequency of flashes $N$ (normalized per $1 \mathrm{~m}$, and $100 \mathrm{~m}$, respectively) that exceed the threshold (Fig. 8 second from left). In the upper panel, the largest $\chi$ of more than 10 can be found in $50 \mathrm{~cm}$ depth, which is associated with 2 to $5 \mathrm{~cm}$ long waves. A reason for the comparably moderate $\chi_{\max }$ is the presence of strong wind $\left(11 \mathrm{~m} \mathrm{~s}^{-1}\right)$, which impairs the efficiency of generating lens-surfaces for intense focusing. In general, the strongest near-surface fluctuations appear at relatively low wind of less than $6 \mathrm{~m} \mathrm{~s}^{-1}$ (Dera and Stramski, 1986; Gernez and Antoine, 2009), and $\chi$ can be larger than 13 (Gernez et al., 2011). According to the simulations with "perfect" single waves, the theoretical $\chi_{\max }$ lies in the order of approximately 20 at $50 \mathrm{~cm}$ depth. In the same manner as the $P D F$, the flash occurrence distributions increase rapidly within the first $50 \mathrm{~cm}$ and then they slowly decrease. Our model with $d x=10 \mathrm{~cm}$ spatial resolution shows light flashes of $\chi=1.5$ even down to $35 \mathrm{~m}$ water depth, which is much deeper than so far observed with temporal irradiance measurements. In the particular case the occurrence of light flashes at this depth range is directly associated with the sea state parameters, namely the superposition of around $40 \mathrm{~m}$ long waves (from the wind sea) with the $140 \mathrm{~m}$ swell, and it is independent of the local wind situation.

The depth-development of the coefficient of variation $C V$ is shown in the panels Fig. 8 second from right. The fundamental curve progression and the orders of magnitudes of $C V$, which depend on the resolution, correspond to previous observations (e.g. Nikolayev and Khulapov, 1976; Gernez and Antoine, 2009; Hieronymi and Macke, 2010; D'Alimonte et al., 2010; Weber, 2010). The figure shows that underwater light field fluctuations occur even in $100 \mathrm{~m}$ depth, where (with the specified irregular wave profile) $C V$ is still about $3 \%$. However, wave-induced light fluctuations depend on local wind and the peculiarity of the sea state. According 

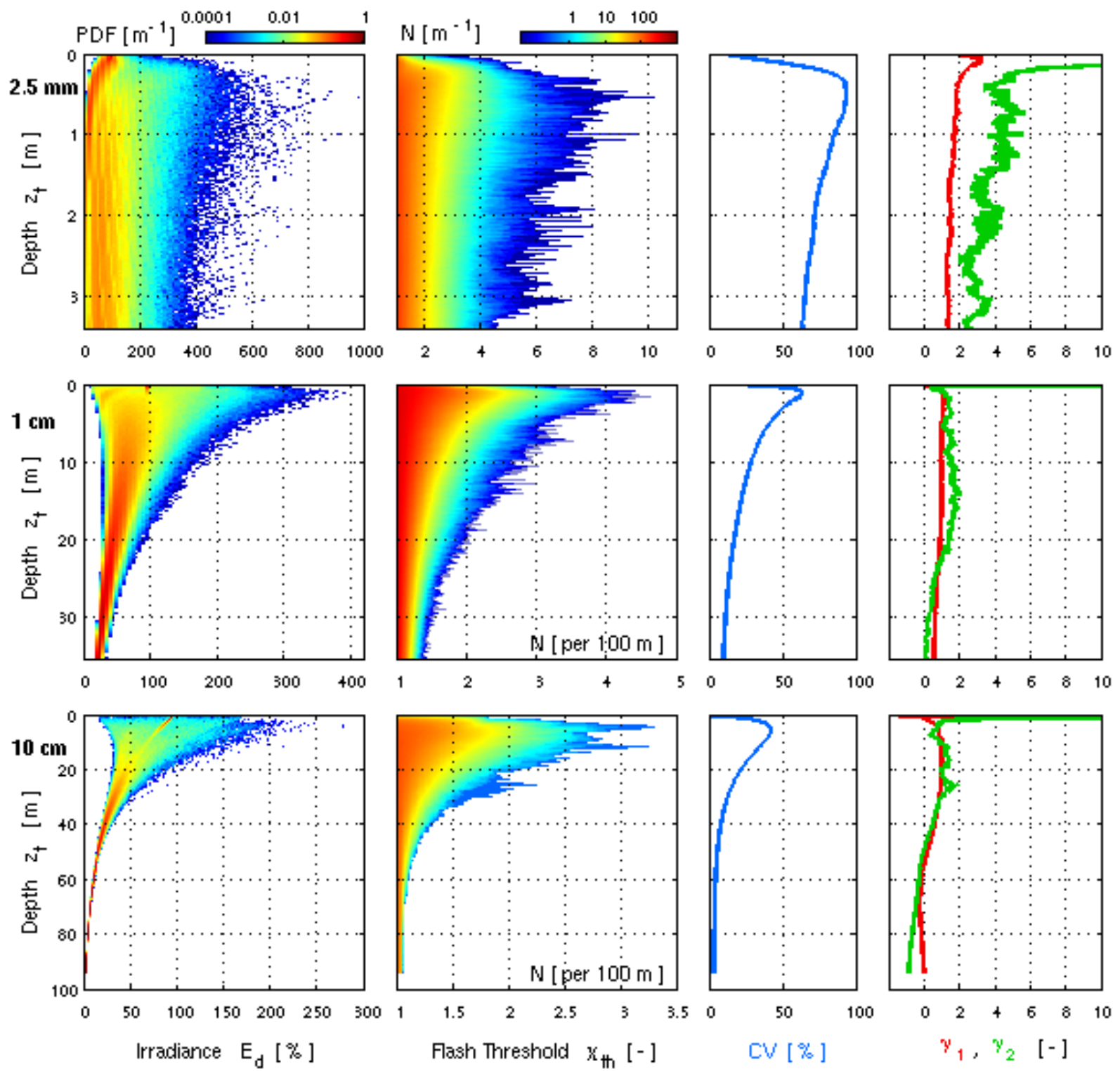

Fig. 8. Statistical evaluation of the modeled light field for 30 October 2009; top: near the surface with $2.5 \mathrm{~mm}$ resolution, middle row: $d x=1 \mathrm{~cm}$, and lower panels: $d x=10 \mathrm{~cm}$; each shown the probability density function $P D F$, frequency of flashes $N$ above a certain threshold $\chi_{\text {th }}$, coefficient of variation $C V$, and $P D F$ skewness $\gamma_{1}$, and excess kurtosis $\gamma_{2}$.

to a theoretical study by Weber (2010), $C V$ exhibits a bimodal dependence on the depth, with a near-surface $C V$ maximum that shifts towards smaller depths with increasing wind velocity, a local $C V$ minimum, which is around a depth of $300 \mathrm{~m}$ in clear oceanic water, and a second maximum, which is located at "fairly large optical depths" (investigations down to $10^{5} \mathrm{~m}$ water depth). Our model considers depths to $100 \mathrm{~m}$ only; here the remaining irradiance is small and the fraction of unscattered light is less than $0.1 \%$ compared to the total downwelling irradiance with the given input parameters. Figure 4 documents the dwindling ability all wave types to focus light within the top $100 \mathrm{~m}$. Thus, the wave-influence on the subsurface light field, and especially $C V$, beyond $300 \mathrm{~m}$ water depth cannot be confirmed with our work. The unique influence of local wind and especially the development of the sea state have to be subject to further analysis.

The skewness $\gamma_{1}$ and excess kurtosis $\gamma_{2}$ of the PDFs are shown on the right side of Fig. 8. The skewness of the irradiance distribution is a measure for the deflection direction of extreme intensity peaks. Above $54 \mathrm{~m}$ the $E_{\mathrm{d}}$ distributions are right-skewed, i.e. more intense radiative enhancements appear than $E_{\mathrm{d}}$ reductions. Below that depth the distribution is slightly negatively skewed. The excess kurtosis is a measure for the peakedness of the irradiance distribution 
compared to a Gaussian distribution (kurtosis minus 3). Positive excess kurtosis means that a larger part of the variance results from extreme intensity peaks. With increasing depth the PDFs become more grouped around the mean value. In principle, all model sizes deliver equivalent results. Slight deviations result from the different resolutions. Generally, the depth-dependency of our simulated $P D F$ skewness and excess kurtosis fits to high-frequency irradiance measurements by Gernez et al. (2011). They show that close to the surface $(<1 \mathrm{~m})$, these parameters can assume values larger than 3 and 20, respectively (the same maximum values in our case), and that both are reduced to nearly zero at $10 \mathrm{~m}$ depth (they refer to $532 \mathrm{~nm}$ wavelength and more turbid water). In addition, they suggest that the skewness and excess kurtosis of the downwelling irradiance $P D F$ could be used to partition the oceanic photonic zone into the sunny and diffuse layer, expressions that are introduced by Dera (1970) to essentially differentiate the areas with and without light flashes. According to this, the depth of the sunny layer bottom is where both, $\gamma_{1}$ and $\gamma_{2}$, approach zero. In our simulations with $d x=10 \mathrm{~cm}$, the skewness and the excess kurtosis approach zero at about $50 \mathrm{~m}$. The precision of our statistical results could be increased by considering a light field of more than $400 \mathrm{~m}$ width (from a $500 \mathrm{~m}$ wave profile) and thus more regarding the impacts on the PDF (especially in greater water depths) of swell waves, which are $140 \mathrm{~m}$ long in the considered case (swell period $9.5 \mathrm{~s}$ ). Our model provides comprehensible and logical statistical results down to $100 \mathrm{~m}$ depth and furthermore, it is the first model that gives such high-resolution information on wave-induced light field fluctuations.

\section{Conclusions}

We developed a novel radiative transfer model for simulating light field fluctuations (that are caused by surface waves) down the water column. The spatial propagation of solar radiation in water, i.e. the light scattering and absorption, is calculated by means of a special Monte Carlo radiative transfer procedure. The model is generally adaptive for several variables, such as the electromagnetic wavelength, inherent optical properties of seawater, different lighting conditions, different light field resolutions, and above all for arbitrary sea surface structures, for which the model is optimized. The resulting underwater light fields, which are quantified by the distribution of the downwelling irradiance, cover large 2-D domains with comparable high spatial resolution $(2.5 \mathrm{~mm}$ to $10 \mathrm{~cm}$ ) and great depths (down to $100 \mathrm{~m}$ ). Vertical deflections of irregular sea surfaces, in orders of magnitude between capillary and fully developed gravity waves, can be implemented into the model. The model is relatively fast (since the Monte Carlo procedure is decoupled from geometric ray tracing) and it provides all statistical properties of the light regime. The modeled fluctuation characteristics fit to previously pub- lished observations, and beyond this, show a high information density into much greater depths (to $100 \mathrm{~m}$ ). The mean values of the downwelling irradiance are within the usual error margins compared to offshore measurements and other radiometric transfer models, as e.g. HydroLight. Thus, the introduced radiative transfer model provides some important advantages compared to other current models (Deckert and Micheal, 2006; D'Alimonte et al., 2010; You et al., 2010).

By means of the model, underwater light variability was simulated for different single waves and for realistic wave situations in the open ocean. The latter agree well with equivalent in-situ measurements. The model parameters are selected in such a manner that maximum irradiance variability can be achieved, i.e. monochromatic light at $490 \mathrm{~nm}$, very clear water, and high sun elevation are used for the calculations. Simulations have been performed for more than 300 nonlinearly shaped single waves of all sizes that appear in the open ocean. In general, the depth-impact of waves depends on their length and steepness, the longer the wave the deeper is its potential influence. We provide expectation values of maximum possible wave focusing per depth, e.g. at $1 \mathrm{~m}$ water depth light flashes can theoretically exceed the mean irradiance by a factor of 40 (with $d x=2.5 \mathrm{~mm}$ ). The greatest theoretically possible depth of light flashes with $50 \%$ radiative enhancement should be around $80 \mathrm{~m}$ (with $d x=10 \mathrm{~cm}$ ), which would be caused by a very steep $(H / L=0.09)$ gravity wave over $60 \mathrm{~m}$ long. Even $200 \mathrm{~m}$ long swell waves can develop $E_{\mathrm{d}}$ fluctuations within a range of $\pm 15 \%$ compared to the mean value below $90 \mathrm{~m}$ of water depth.

The superposition of short and long waves from the ocean wave spectrum at the water surface leads to characteristic probability distributions of downwelling irradiance in the water column. Local wind primarily affects the development and steepness of capillary and gravity-capillary waves of 0.7 to $3 \mathrm{~cm}$ length, with a typical high-frequency peak in the wave spectrum at $1.7 \mathrm{~cm}$. The resulting irradiance maxima due to those gravity-capillary wave lenses can be found within the top $1 \mathrm{~m}$ near the surface. A further deflection of light beams is forced by overlaying ultra-gravity waves (less than $1 \mathrm{~m}$ long), which are already much less directly winddependent. This leads to intensified light beam grouping at 1 to $4 \mathrm{~m}$ depth, but certainly with decreasing frequency of the occurrence of extreme light flashes. We suggest that the influence of local wind on light fluctuations is restricted to approximately the upper $10 \mathrm{~m}$ of the water column. Below this layer, light variability is obviously driven by longer and thus more developed waves. With increasing water depth, light fluctuation periodicity adapts more and more to the longwave part of the sea spectrum, i.e. to the dominant wave of the sea state.

Our model results of natural irregular light fields suggest that light flashes with $50 \%$ irradiance enhancements can appear even in $35 \mathrm{~m}$ depth (with low occurrence probability). In addition, under high sea conditions light variability of less than $\bar{E}_{\mathrm{d}} \pm 10 \%(C V<5 \%)$ is possible still in $100 \mathrm{~m}$ depth. 
The modeling results have to be verified with adequate insitu measurements at sea; our deepest measured light flash was at about $20 \mathrm{~m}$ depth.

Certainly, a future question is the relevance of this deepwater light variability for different photo-relevant processes. Below approximately $10 \mathrm{~m}$ depth, the photosynthetically active radiation PAR $(400-700 \mathrm{~nm})$ is strongly dominated by the blue-green spectral components and the used $490 \mathrm{~nm}$ can be considered representative for this waveband. Thus, we suggest that the described fluctuation characteristics at $490 \mathrm{~nm}$ can be a good approximation for the variability of the entire $P A R$ value.

Acknowledgements. This work was supported by the German Research Foundation DFG (contract MA 2225/11-1) and the Kiel Cluster of Excellence "The Future Ocean". We express our gratitude to Curtis D. Mobley for making the HydroLight software available. Model comparative measurements have been carried out in the framework of the OCEANET project on board the R/V Polarstern, cruise ANT-XXVI/1; the assistance of the crew and members of the working group is highly appreciated. Finally, we thank the editor John M. Huthnance and the anonymous reviewers for suggestions that improved the paper.

Edited by: J. M. Huthnance

\section{References}

Babanin, A. V.: On a wave-induced turbulence and a wavemixed upper ocean layer, Geophys. Res. Let., 33, L20605, doi:10.1029/2006GL027308, 2006.

Cox, C. and Munk, W.: Measurements of the roughness of the sea surface from photographs of the sun's glitter, J. Opt. Society Am., 44, 838-850, 1954.

Cullen, J. J.: The deep chlorophyll maximum: comparing vertical profiles of chlorophyll a, Can. J. Fish. Aquat. Sci., 39, 791-803, doi:10.1139/f82-108, 1982.

D'Alimonte, D., Zibordi, G., Kajiyama, T., and Cunha, J. C.: Monte Carlo code for high spatial resolution ocean color estimation, Appl. Opt., 49, 4936-4950, doi:10.1364/AO.49.004936, 2010.

Darecki, M., Stramski, D., and Sokolski, M.: Measurements of high-frequency light fluctuations induced by ocean surface waves with an underwater porcupine radiometer system, J. Geophys. Res., 116, C00H09, doi:10.1029/2011JC007338, 2011.

de Boyer Montegut, C., Madec, G., Fischer, A. S., Lazar, A., and Iudicone, D.: Mixed layer depth over the global ocean: An examination of profile data and a profile-based climatology, J. Geophys. Res., 109, C12003, doi:10.1029/2004JC002378, 2004.

Deckert, R. and Michael, K. J.: Lensing effect on underwater levels of UV radiation, J. Geophys. Res., 111, C05014, doi:10.1029/2005JC003332, 2006.

Dera, J.: On two layers of different light conditions in the euphotic zone in the sea, Acta Geophys. Pol., 18, 287-294, 1970.

Dera, J. and Gordon, H. R.: Light field fluctuations in the photic zone, Limnol. Oceanogr., 13, 697-699, 1968.

Dera, J. and Stramski, D.: Maximum effects of sunlight focusing under a wind-disturbed sea surface, Oceanologia, 23, 15-42, 1986.
Dickey, T., Granata, T., Marra, J., Langdon, C., Wiggert, J., ChaiJochner, Z., Hamilton, M., Vazquez, J., Stramska, M., Bidigare, R., and Siegel, D.: Seasonal variability of bio-optical and physical properties in the Saragasso Sea, J. Geophys. Res., 98, 865898, doi:10.1029/92JC01830, 1993.

Dickey, T. D., Kattawar, G. W., and Voss, K. J.: Shedding new light on light in the ocean, Phys. Today, 64, 44-49, doi:10.1063/1.3580492, 2011.

Elfouhaily, T., Chapron, B., Katsaros, K., and Vandemark, D.: A unified directional spectrum for long and short wind-driven waves, J. Geophys. Res., 102, 15781-15796, doi:10.1029/97JC00467, 1997.

El Naggar, S. and Macke, A. (Ed.): The expedition of the Research Vessel "Polarstern" to the Antarctic in 2009 (ANTXXVI/1), Reports on Polar and Marine Research, 614, 79 pp., doi:10013/epic.35280, 2010.

Falkowski, P. G.: Physiological responses of phytoplankton to natural light regimes, J. Plankton Res., 6, 295-307, doi:10.1093/plankt/6.2.295, 1984.

Fell, F. and Fischer, J.: Numerical simulation of the light field in the atmosphere-ocean system using the matrix-operator method, J. Quant. Spectrosc. Ra., 69, 351-388, doi:10.1016/S00224073(00)00089-3, 2001.

Fraser, A. B., Walker, R. E., and Jurgens, F. C.: Spatial and temporal correlation of underwater sunlight fluctuations in the Sea, IEEE J. Oceanic Eng., 5, 195-198, doi:10.1109/JOE.1980.1145467, 1980.

Furuya, K.: Subsurface chlorophyll maximum in the tropical and subtropical western Pacific Ocean: vertical profiles of phytoplankton biomass and its relationship with chlorophyll a and particulate organic carbon, Mar. Biol., 107, 529-539, doi:10.1007/BF01313438, 1990.

Gernez, P. and Antoine, D.: Field characterization of waveinduced underwater light field fluctuations, J. Geophys. Res., 114, C06025, doi:10.1029/2008JC005059, 2009.

Gernez, P., Stramski, D., and Darecki, M.: Vertical changes in the probability distribution of downwelling irradiance within the near-surface ocean under clear sky conditions, J. Geophys. Res., 116, C00H07, doi:10.1029/2011JC007156, 2011.

Gordon, H. R. and Morel, A.: Remote assessment of ocean color for interpretation of satellite visible imagery, A review, in: Lecture Notes on Coastal and Estuarine Studies, edited by: Barber, R. T., Mooers, C. N. K., Bowman, M. J., and Zeitzchel, B., Springer, New York, 114 pp., 1983.

Hieronymi, M.: Solar radiative transfer into the ocean: A study on underwater light fluctuations due to surface waves, $\mathrm{Ph} . \mathrm{D}$. thesis, Christian-Albrechts-Universität zu Kiel, Germany, 103 pp., 2011.

Hieronymi, M. and Macke, A.: Spatiotemporal underwater light field fluctuations in the open ocean, J. Europ. Opt. Soc. Rap. Public., 5, 1-8, 10019S, doi:10.2971/JEOS.2010.10019S, 2010.

Hogben, N. and Lumb, F. E.: Ocean wave statistics, HMSO, London, 1967.

Jähne, B. and Riemer, K. S.: Two-dimensional wave number spectra of small-scale water surface waves, J. Geophys. Res., 95, 1153111546, doi:10.1029/JC095iC07p11531, 1990.

Kantha, L.: A note on the decay rate of swell, Ocean Modell., 11, 167-173, doi:10.1016/j.ocemod.2004.12.003, 2006.

Kinsman, B.: Wind Waves: their generation and propagation on the 
ocean surface, Englewood Cliffs, N. J., Prentice-Hall, 1965.

Kirk, J. T. O.: Monte Carlo study of the nature of the underwater light field in, and the relationship between optical properties of, turbid yellow water, Aust. J. Mar. Freshwater Res., 32, 517-532, doi:10.1071/MF9810517, 1981.

Longuet-Higgins, M. S.: The effect of non-linearities on statistical distributions in the theory of sea waves, J. Fluid Mech., 17, 459480, doi:10.1017/S0022112063001452, 1963.

Longuet-Higgins, M. S.: On the skewness of sea-surface slopes, J. Phys. Oceanogr., 12, 1283-1291, doi:10.1175/15200485(1982)012<1283:OTSOSS > 2.0.CO;2, 1982.

Macke, A.: Monte Carlo calculations of light scattering by large particles with multiple internal inclusions, in: Light scattering by nonspherical particles: Theory, measurements, and applications, edited by: Mishchenko, M. I., Hovenier, J. W., and Travis, L. D., San Diego, Academic Press, 309-322, 2000.

Marcos, M., Seymour, J. R., Luhar, M., Durham, W. M., Mitchell, J. G., Macke, A., and Stocker, R.: Microbial alignment in flow changes ocean light climate, P. Natl. Acad. Sci. USA, 108, 10, 3860-3864, doi:10.1073/PNAS.1014576108, 2011.

Mobley, C. D.: Light and water: Radiative transfer in natural waters, San Diego, Academic Press, 592 pp., 1994.

Mobley, C. D., Gentili, B., Gordon, H. R., Jin, Z., Kattawar, G. W., Morel, A., Reinersman, P., Stamnes, K., and Stavn, R. H.: Comparison of numerical models for computing underwater light fields, Appl. Opt., 32, 7484-7504, doi:10.1364/AO.32.007484, 1993.

Morel, A.: Optical modeling of the upper ocean in relation to its biogenous matter content (Case 1 waters), J. Geophys. Res., 93, 10749-10768, doi:10.1029/JC093iC09p10749, 1988.

Morel, A.: Are the empirical relationships describing the bio-optical properties of case 1 waters consistent and internally compatible?, J. Geophys. Res., 114, C01016, doi:10.1029/2008JC004803, 2009.

Morel, A. and Gentili, B.: Diffuse reflectance of oceanic waters: its dependence on sun angle as influenced by the molecular scattering contribution, Appl. Opt., 30, 4427-4438, doi:10.1364/AO.30.004427, 1991.

Morel, A. and Prieur, L.: Analysis of variations in ocean color, Limnol. Oceanogr., 22, 709-722, 1977.

Morel, A., Antoine, D., and Gentili, B.: Bidirectional reflectance of oceanic waters: accounting for Raman emission and varying particle scattering phase function, Appl. Opt., 41, 6289-6306, doi:10.1364/AO.41.006289, 2002.

Morel, A., Gentili, B., Claustre, H., Babin, M., Bricaud, A., Ras, J., and Tieche, F.: Optical properties of the "clearest" natural waters, Limnol. Oceanogr., 52, 217-229, doi:10.4319/LO.2007.52.1.0217, 2007.

Nikolayev, V. P. and Khulapov, M. S.: Use of a nonstatistical model to explain the mechanism of underwater illumination fluctuations, Izv. Atmospheric and Oceanic Physics, 12, 993-997, 1976.

Nikolayev, V. P. and Prokopov, O. I.: The relationship between the statistical characteristics of underwater illumination and certain lighting conditions of the sea surface, Izv. Atmospheric and Oceanic Physics, 13, 734-738, 1977.

Nikolayev, V. P. and Yakubenko, V. G.: On the relationship between the statistical characteristics of the underwater light field and the wave state characteristics, Izv. Atmospheric and Oceanic Physics, 14, 88-92, 1978a.
Nikolayev, V. P. and Yakubenko, V. G.: Experimental research into the spatial structure of the fluctuations of the underwater light field, Izv. Atmospheric and Oceanic Physics, 14, 301-305, 1978b.

Nikolayev, V. P., Prokopov, O. I., Rozenberg, G. V., and Shevernev, V. I.: Statistical properties of the underwater illumination, Izv. Atmospheric and Oceanic Physics, 8, 936-944, 1972.

Ochi, M. K. and Hubble, E. N.: Six-parameter wave spectra, Proc. 15th Coastal Engineering Conf., 301-328, 1976.

Petzold, T. J.: Volume scattering functions for selected ocean waters, Scripps Institution of Oceanography, San Diego, Ref. 72 78, 1972.

Plass, G. N. and Kattawar, G. W.: Monte Carlo calculations of radiative transfer in the Earth's atmosphere-ocean system: 1. Flux in the atmosphere and ocean, J. Phys. Oceanogr., 2, 139-145, doi:10.1175/1520-0485(1972)002<0139:MCCORT>2.0.CO;2, 1972.

Plass, G. N., Kattawar, G. W., and Guinn Jr., J. A.: Radiative transfer in the earth's atmosphere and ocean: influence of ocean waves, Appl. Opt., 14, 1924-1936, doi:10.1364/AO.14.001924, 1975.

Pope, R. M. and Fry, E. S.: Absorption spectrum (380-700 nm) of pure water. II. Integrating cavity measurements, Appl. Opt., 36, 8710-8723, doi:10.1364/AO.36.008710, 1997.

Preisendorfer, R. W. and Mobley, C. D.: Albedos and glitter patterns of a wind-roughened sea surface, J. Phys. Oceanogr., 16, 1293-1316, doi:10.1175/15200485(1986)016<1293:AAGPOA > 2.0.CO;2, 1986.

Schenck Jr., H.: On the focusing of sunlight by ocean waves, J. Opt. Soc. Am., 47, 653-657, doi:10.1364/JOSA.47.000653, 1957.

Segelstein, D. J.: The complex refractive index of water, MS thesis, University of Missouri, Kansas City, 1981.

Snyder, R. L. and Dera, J.: Wave-induced light field fluctuations in the Sea, J. Opt. Soc. Am., 60, 1072-1079, doi:10.1364/JOSA.60.001072, 1970.

Sterl, A. and Caires, S.: Climatology, variability and extrema of ocean waves: The web-based NKMI/ERA-40 wave atlas, Int. J. Climatol., 25, 963-977, doi:10.1002/JOC.1175, 2005.

Stramski, D. and Dera, J.: On the mechanism for producing flashing light under a wind-disturbed water surface, Oceanologia, 25, 521,1988

Stramski, D. and Tegowski, J.: Effects of intermittent entrainment of air bubbles by breaking wind waves on ocean reflectance and underwater light field, J. Geophys. Res., 106, 31345-31360, doi:10.1029/2000JC000461, 2001.

Walker, R. E.: Marine light field statistics, Wiley Series in Pure and Applied Optics, p. 675, ISBN 0471310468, 1994.

Walsh, P. and Legendre, L.: Photosynthesis of natural phytoplankton under high frequency light fluctuations simulating those induced by sea surface waves, Limnol. Oceanogr., 28, 688-697, 1983.

Wang, M., Knobelspiesse, K. D., and McClain, C. R.: Study of the Sea-Viewing Wide Field-of-View Sensor (SeaWiFS) aerosol optical property data over ocean in combination with the ocean color products, J. Geophys. Res., 110, D10S06, doi:10.1029/2004JD004950, 2005.

Weber, V. L.: Coefficient of variation of underwater irradiance fluctuations, Radiophysics and Quantum Electronics, 53, 13-27, 2010. 
Wijesekera, H. W., Pegau, W. S., and Boyd, T. J.: Effects of surface waves on the irradiance distribution in the upper ocean, Opt. Express, 13, 9257-9264, doi:10.1364/OPEX.13.009257, 2005.

Wozniak, B., Dera, J., Ficek, D., Majchrowski, R., Ostrowska, M., and Kaczmarek, S.: Modelling light and photosynthesis in the marine environment, Oceanologia, 45, 171-245, 2003.

Yakubenko, V. G. and Nikolayev, V. P.: Numerical modeling of the fluctuations of the light field beneath a rough sea surface, Izv. Atmospheric and Oceanic Physics, 13, 135-139, 1997.

You, Y., Stramski, D., Darecki, M., and Kattawar, G. W.: Modeling of wave-induced irradiance fluctuations at the near-surface depths in the ocean: a comparison with measurements, Appl. Opt., 49, 1041-1053, doi:10.1364/AO.49.001041, 2010.

Zaneveld, J. R. V., Boss, E., and Barnard, A.: Influence of surface waves on measured and modeled irradiance profiles, Appl. Opt., 40, 1442-1449, doi:10.1364/AO.40.001442, 2001.
Zhang, X., He, M. X., Yang, Q., and Zeng, K.: Effects of wind on ocean color, IGARSS 2006, 4056-4059, doi:10.1109/IGARSS.2006.1040, 2006.

Zibordi, G. and Voss, K. J.: Geometrical and spectral distribution of sky radiance: Comparison between simulations and field measurements, Remote Sens. Environ., 27, 343-358, doi:10.1016/0034-4257(89)90094-1, 1989.

Zibordi, G., D'Alimonte, D., and Berthon, J. F.: An evaluation of depth resolution requirements for optical profiling in coastal waters, J. Atmos. Ocean. Tech., 21, 1059-1073, 2004.

Zielinski, O., Llinás, O., Oschlies, A., and Reuter, R.: Underwater light field and its effect on one-dimensional ecosystem model at station ESTOC, north of the Canary Islands, Deep-Sea Res. Pt. II, 49, 3529-3542, doi:10.1016/S0967-0645(02)00096-6, 2002. 